\title{
Turning of Inconel 718 Using Liquid Nitrogen: Multi- objective Optimization of Cutting Parameters Using RSM
}

\section{Behzad Eskandari}

University of Windsor

\section{Sukanta Bhowmick}

University of Windsor

Ahmet Alpas ( $\nabla$ aalpas@uwindsor.ca )

University of Windsor

\section{Research Article}

Keywords: Inconel 718, Cryogenic cutting, multi-objective optimization, Response surface methodology (RSM), Wear mechanisms, Surface quality

Posted Date: November 30th, 2021

DOI: https://doi.org/10.21203/rs.3.rs-1101476/v1

License: (a) (1) This work is licensed under a Creative Commons Attribution 4.0 International License. Read Full License

Version of Record: A version of this preprint was published at The International Journal of Advanced Manufacturing Technology on March 1st, 2022. See the published version at https://doi.org/10.1007/s00170-022-08906-w. 


\section{Abstract}

The objective of this research was to investigate the effectiveness of application of liquid nitrogen $\left(\mathrm{LN}_{2}\right)$ in turning of Inconel 718 compared to flooded cutting and select suitable $\mathrm{LN}_{2}$ cutting parameters using response surface methodology (RSM). The results of turning experiments conducted by spraying $\mathrm{LN}_{2}$ to the cutting area of Inconel 718 bar showed that using either low or high cutting parameters, cutting performance of Inconel 718 under the cryogenic condition was generally worse than the flooded cutting. However, using the medium cutting parameters the cutting performance was as good as flooded cutting showing the values of $90 \mathrm{~N}$ of cutting force, $60 \mu \mathrm{m}$ of flank wear and $0.5-0.6 \mu \mathrm{m}$ of surface roughness (Ra). These parameters were further optimized using desirability function of RSM to determine the set of parameters that provide the lowest cutting force, flank wear and $\mathrm{Ra}$ and the highest material removal rate (MRR) under cryogenic cutting. Analysis of variance (ANOVA) performed on the developed regression models showed that cutting speed was the significant factor on cutting force. Feed rate was the most influential parameter on flank wear. Feed rate and depth of cut was significant factors affecting Ra. Multiobjective optimization showed that a cutting speed of $87 \mathrm{~m} / \mathrm{min}$, a feed rate of $0.06 \mathrm{~mm} / \mathrm{rev}$ and a depth of cut of $0.37 \mathrm{~mm}$ constituted the optimum cutting parameters for achieving the, cutting force of $78 \mathrm{~N}$, flank wear of $58 \mu \mathrm{m}$, Ra of $0.49 \mu \mathrm{m}$ and the MRR of $1.97 \mathrm{~cm}^{3} / \mathrm{min}$ under cryogenic cutting condition.

\section{Introduction}

Inconel 718 is a widely used nickel-based superalloy with high corrosion and creep resistance for elevated temperature applications. This provides challenges during machining due to retention of strength at elevated temperatures, high strain and strain-rate hardening, low thermal conductivity and presence of hard carbide particles in its microstructure [1]. As a result, generally tool wear [2-4] and cutting forces are high and the machined surfaces has low quality $[5,6]$. Various methods have been proposed to facilitate cutting process during machining of nickel-based superalloys including high-pressure machining [7], utilization of nano-fluids [8], laser-assisted machining [9], heat-assisted machining [10,11] and hybrid machining (application of two or more of the mentioned cutting conditions at the same time) [12]. Another effective method is application of a cryogen (liquefied gas such as liquid nitrogen or $\mathrm{CO}_{2}$ ) during the cutting process. Response surface methodology (RSM) is a statistical analysis method which is used for designing the experiments and optimizing the process parameters [13-15]. It has been employed for optimization of manufacturing processes of various alloys including superalloys [16-18]. The use of RSM could determine the set of machining parameters under which these new cutting methods could provide high machining efficiency and low tool wear. The literature survey presented in the following parts of this section therefore summarizes the previous experimental works on cryogenic machining of nickelbased superalloys and also reviews the related statistical analyses methods for the optimization of machining parameters.

Cryogenic cutting is considered as a clean production method since liquid nitrogen $\left(\mathrm{LN}_{2}\right)$ evaporates instantly, leaving the machined workpiece dry and free of cutting fluid films and contaminants. Although 
the cost of $\mathrm{LN}_{2}$ could be higher than flooded cutting, it has the advantage of eliminating post-cutting cleaning and recycling process. Operating the machining process using cryogens would increase the rate of heat dissipation and alleviate some of the issues related to high temperature generation the toolworkpiece interface. Mechanical properties of the workpiece material especially for steel and other the body centered cubic (bcc) and some hexagonal close packed, hcp, like titanium alloys are sensitive to low temperatures and may lead to improved machinability. Machining practices in which cryogens were applied to the cutting area dates back to 1919 [19]. Some researchers have applied the cryogen on the workpiece material by immersing the material into the cryogen [20] while other researchers have sprayed it onto the cutting area [21] or the combination of these techniques [22]. Cryogenic cooling during the machining process has several effects on machining performance including (1) changing the mechanical properties of the workpiece and tool materials (increase in hardness, modulus of elasticity and strength of materials). (2) removing the heat generated during the machining process and (3) change in frictional characteristics of the tool-chip and tool-workpiece interfaces [23, 24].

Cryogenic machining of Inconel 718 has been studied in comparison with other machining methods by spraying the $\mathrm{LN}_{2}$ to the cutting area in the past studies. Kaynak [25] conducted a comparative study of cryogenic cutting of Inconel 718 with dry and minimum quantity lubrication (MQL) machining, and observed that flank wear was the lowest compared to MQL and dry turning - the difference increased as the cutting speed increased. The surface roughness generated during cryogenic machining was lower than MQL and dry cutting.

Some researchers observed that cryogenic machining can lead to improvements of certain machining parameters but deterioration others when compared to flooded cutting of Inconel 718. Stephenson et al. [26] conducted rough turning tests on Inconel 750 using carbide tools under cryogenic machining with $\mathrm{CO}_{2}-\mathrm{MQL}$ coolant and compared the results with aqueous flooded cutting. Cryogenic machining resulted in less flank and notch wear; however, it increased the crater wear. Additionally, material removal rate increased up to $40 \%$ during cryogenic machining.

Iturbe et al. [27] reported that tool life in flood cutting of Inconel 718 was 20 min while it was 7 min for cryogenic cooling. The results also showed that Ra surface roughness at the same flank wear values were doubled for cryogenic machining $(2 \mu \mathrm{m})$ compared to flooded cutting $(1 \mu \mathrm{m})$. Moreover, depth of subsurface microstructural damage in cryogenic cutting was four times higher than the conventional flooded cutting. Tebaldo et al. [28] conducted turning experiments on Inconel 718 under different cooling conditions namely dry, flooded, MQL and minimum quantity cooling (MQC) at different cutting speeds using cemented carbide tools. Taylor wear curves showed that at a constant tool life (15 min), the maximum cutting speed used under flooded cutting was $51 \mathrm{~m} / \mathrm{min}$ and $47 \mathrm{~m} / \mathrm{min}$ for MQC and MQL whereas $49 \mathrm{~m} / \mathrm{min}$ for MQC. Additionally, the tool subjected to cryogenic temperatures was reported to be subjected to a higher thermal shock causing fracture.

Response Surface Methodology (RSM) is a powerful tool for systematic investigation of effect of process parameters on the response factors [29]. However, there are few works on optimization of parameters 
under cryogenic machining of superalloys. Most of the previous reports on cryogenic machining of Inconel 718 were based on experiments that were conducted at cutting parameters that were either randomly selected or were conceived to be the most important ones according to the researchers. Although the parameters used in these experiments were generally consistent with those recommended by the manufacturers, the selection of the cutting parameters used in the laboratory experiments can be improved using RSM. Thus, a systematic approach has been adopted in the current research to determine an optimum set of machining parameters [30].

Although cryogenic machining has several advantages, the above literature survey shows that cryogenic machining does not always improve the machining parameters nor the surface quality. Consequently, it has not been implemented in machining industries as a viable practice. The question that which set of parameters should be used during the cryogenic machining to obtain an overall favourable performance which is comparable to conventional flooded cutting is yet to be answered. Pusavec et al. [31] have attempted to address this question by optimizing the cutting parameters using RSM. However, they compared cryogenic cooling with MQL and Cryo/MQL. According to the results, cryo-MQL showed the better results in terms of tool wear and cutting force. Speed of $42.3 \mathrm{~m} / \mathrm{min}$, feed of $0.05 \mathrm{~mm} / \mathrm{rev}$ and depth of cut of $0.88 \mathrm{~mm}$ were found to be optimum cutting parameters. The novelty of this work is to investigate the machining behaviour of Inconel 718 under cryogenic cutting at broad range of machining parameters, namely low, medium and high cutting speeds and feed rates in comparison to the conventional flooded cutting. There are a few papers on the comparison of conventional flooded and cryogenic machining of Inconel 718; however, in these studies fixed cutting parameters were used for conducting the experiments. This research aims to fill this gap by, first comparing the results from cutting Inconel 718 by using a setup of pouring $\mathrm{LN}_{2}$ to the cutting area with the conventional flooded and dry cutting processes in terms of cutting force, flank wear and Ra surface roughness at different cutting speeds and feed rates. The main objective was to evaluate the machining behaviour of Inconel 718 under the application of $\mathrm{LN}_{2}$ to the cutting area compared to flooded cutting. Based on the results from this comparison, cryogenic cutting performed as good as flooded cutting at medium cutting parameters. Hence, in order to find a set of optimum cutting parameters, central composite design (CCD) of response surface methodology (RSM) was employed to design the experiments and the optimum parameters was determined by using desirability function of RSM. Statistical analyses were employed in order to investigate the effect of cutting parameters on the response factors, namely flank wear, cutting force, Ra surface roughness and material removal rate (MRR) and determine the optimum cutting parameters in cutting using $\mathrm{LN}_{2}$. Cutting speed, feed rate and depth of cut were selected as cutting parameters each in five levels (Section 2).

\section{Materials And Methods}

The turning experiments were conducted on HAAS CNC Lathe using uncoated cemented carbide inserts and a tool holder with the ISO designation of DNGG150402 and PDJNR2020 manufactured by Sandvik Cormorant. The cross-sectional analysis of the cutting edge of the tool showed that the rake angle was 
$+9^{\circ}$. To prevent ploughing action, and consequently, lower plastic deformation during the cutting process, tool radius was selected at the lower amount $(0.2 \mathrm{~mm})$ and the depth of cut was selected to be more than tool radius [32].

Hot rolled bars of Inconel 718 with the composition (wt.\%) of Ni 53.84, Fe 18.02, $\mathrm{Cr} 17.98$, (Nb+Ta) 5.39, $\mathrm{Nb} 5.38$, Mo 2.92, Ti 0.96, Al 0.47, Co 0.35, Mn 0.09, Si 0.08, Cu 0.05, C 0.02, P 0.01, B 0.004, S 0.0003, Ta $<0.01, \mathrm{Mg}<0.01$, and $\mathrm{Ca}<10$ PPM were used as the workpiece material. The samples were solution treated with the cycle consisting of heating to $955 \llbracket \mathrm{C}$ and holding for 1 hour and then quenched in water.

Cryogenic cutting experiments were conducted using a rotating pump mounted to a flask containing $\mathrm{LN}_{2}$ to spray the liquid nitrogen on the cutting edge of the tool and contact surface of the workpiece. The experimental setup and application of $\mathrm{LN}_{2}$ to the cutting area is shown in Figure $1 \mathrm{a}, \mathrm{b}$. The flooded cutting experiments were conducted by applying synthetic cutting fluid. The microstructure of the Inconel 718 workpiece is shown in Figure 1c.

Linear strain gauges mounted on the tool holder were used to measure the cutting force in the tangential direction. The resistance and gauge factor of the strain gauges were $3.5 \mathrm{k} \Omega$ and 2.08 (Figure 2a). Since the changes in the resistance of strain gauges were very low (usually less than $0.5 \%$ ) [9], a Wheatstone bridge configuration was used [33] (Figure 2b). A 'groove' or reduced gauge section with thinner cross sectional area was machined on the tool holder where the strain gauges were located for measuring elastic deflections during the machining process with high sensitivity. Figure $2 \mathrm{c}$ shows the modified tool holder and the strain gauges attached to the 'groove' on it. The calibration of the measurement set up was done before each cutting experiment by hanging of weights and a linear relationship between the applied load and the output voltage $V_{\text {out }}$ was observed as shown in Figure $2 \mathrm{~d}$. A data acquisition system including a wireless transmitter (V-Link 2.4 GHz Wireless Voltage Node 181) and an analog base receiver (MicroStrain Micro TxRx wireless base station W/ analog outputs) was used to measure the cutting forces during the turning process. More details can be found in the research by Krishnamurthy et al. [20].

Flank wear values were recorded according to ISO 3685:1993 standard by measuring the flank wear land in the $B$ region [34] at least in 10 spots and the average values are reported. After each experiment, the insert was unmounted from the tool holder and its surface was examined using a ZEISS Axio Vert optical microscope at $\times 20$ magnification which was fitted with a camera for measuring the obtained pictures using Image J software.

Vertical Scanning Interferometry (VSI) mode of WYKO NT 1100 optical profilometry system was utilized for 3D measurement of machined surface roughness values. The measurements were done at least in five area of the machined surface.

The results section is presented in two parts: in Section 3.1. the results of a comparison of cryogenic with flooded and dry cutting in terms of flank wear, cutting force and Ra surface roughness are presented. The objective of this part was to investigate the machining bahviour of Inconel 718 at different cutting parameters compared to flooded and dry cutting conditions. 
Section 3.2 tries to find the optimum cutting parameters at which lowest values of cutting force, flank wear and Ra surface roughness was achieved by using desirability function of response surface methodology (RSM). Regression models were developed in order to correlate cutting parameters to the response variables and ANOVA was employed to determine the significance of each cutting parameter using central composite design (CCD) type of the response surface methodology (RSM) by using MINITAB software. Figure 3 shows the design of experiments cube plot. Axial, factorial and center points are illustrated in this figure along with the related test numbers. Axial points estimate the quadratic terms of the model. factorial portion of the design contribute to the estimation of the interaction terms in the second-order model. The center points provide an internal estimate of error and contribute toward the estimation of quadratic terms [35]. Three cutting parameters (cutting speed, feed rate and depth of cut) each at five levels were considered as the process parameters. Material removal rate (MRR), flank wear, cutting force and surface roughness were considered as the response factors. Moreover, statistical analyses and multi-objective optimization of parameters using analysis of variance (ANOVA) and desirability function of RSM in machining using $\mathrm{LN}_{2}$ are given in this section.

\section{Results And Discussions}

\subsection{Comparison of cryogenic cutting with flooded and dry machining}

The objective of this section is to determine any difference in variation of cutting force, flank wear and surface roughness with cutting speed and feed rate when $\mathrm{LN}_{2}$ is applied to the cutting edge in comparison to conventional flooded cutting. In addition, since cryogenic cutting is considered as a type of dry cutting method, the results were also compared to dry machining.

\subsubsection{Effect of cutting parameters on cutting force under different cutting conditions}

Figure $4 a$, $b$ shows the variation of cutting force values in terms of cutting speed and feed rate under cryogenic, flooded and dry conditions. A minimum value of cutting force $(90 \mathrm{~N})$ was seen at $70 \mathrm{~m} / \mathrm{min}$ cutting speed (Figure 4a). This is because of the fact that by increasing the cutting speed to a specific value, flow stress of the workpiece material decreases as a result of increase in the cutting temperature which outperforms the strain hardening effect that increases with cutting speed. Pawade et al. [36] investigated the turning of Inconel 718 and showed that after a critical speed $(60 \mathrm{~m} / \mathrm{min})$, the effect of increase in cutting temperature on the flow stress is more significant than strain hardening. However, further increase in the cutting speed led to higher cutting force. This can be attributed to increase in strain rate hardening when cutting speed is increased. This was confirmed by Iturbe et al. [37] in their study on the machining behaviour of Inconel 718 in which they showed that high strain rate hardening coupled with high cutting temperatures at higher cutting speeds results in high cutting forces.

Figure $4 \mathrm{~b}$ shows that by increasing feed rate, cutting force constantly increased. This is due to increase in uncut chip thickness by increasing feed rate, which in turn, increases the normal load on the tool rake face, resulting in higher friction force and consequently higher cutting force [38]. Variation of cutting force 
with cutting time at different feed rates under cryogenic and flooded cutting is shown in Figure 5 . At the feed rate of $0.01 \mathrm{~mm} / \mathrm{rev}$ under cryogenic cutting (Figure 5a), there was a large variation in cutting force values which was resulted from the fracture of the tool nose and occurrence of large chipping in the minor cutting edge (Section 3.1.2), which in turn, resulted in high surface roughness (Section 3.1.3) at this condition. Cutting force value was smaller $(90 \mathrm{~N})$ and more stable at feed rate of $0.05 \mathrm{~mm} / \mathrm{rev}$ (Figure $5 \mathrm{~b}$ ) under cryogenic cutting, compared to 0.01 and $0.09 \mathrm{rev} / \mathrm{min}$. On the contrary, cutting force had an increasing trend at the feed rate of $0.09 \mathrm{~mm} / \mathrm{rev}$ (Figure $5 \mathrm{c}$ ) and after $4 \mathrm{~s}$ cutting tool started to vibrate which is shown by fluctuation in the cutting force values in Figure $5 \mathrm{c}$. Generally, flooded cutting had more stability in the variation of cutting force with time and tool vibration was less than that of cryogenic cutting.

\subsubsection{Effect of cutting parameters on flank wear under different cutting conditions}

Figure $6 a$, $b$ shows the variation of average flank wear values with cutting speed and feed rate under cryogenic, in comparison with flooded and dry cutting conditions. Flank wear values were recorded according to ISO 3685:1993 standard by measuring the average and maximum flank wear land in the region $B$ and minor flank face [34]. The measurements were done at least in 10 spots and the average values are reported. Flank wear increased with increase in cutting speed as shown in Figure 6a. This is because of increase in cutting temperature which reduces the strength of the tool material promoting abrasion which facilitates the adhesion of workpiece material and formation of built-up edge (BUE) [38].

Figure $6 \mathrm{~b}$ shows that at the feed rate of $0.01 \mathrm{~mm} / \mathrm{rev}$ under cryogenic condition, wear value was high due to tool failure in the side cutting edge because of high chipping (Figure $7 \mathrm{a}, \mathrm{b}$ ). Under dry cutting at low feed rate of $0.01 \mathrm{~mm} / \mathrm{rev}$ (Figure 6b), high flank wear in the form of chipping could also be observed (Figure $7 \mathrm{e}, \mathrm{f}$ ). Catastrophic failure of the cutting edge during cryogenic cutting was also reported in previous studies; Pusavec et al. [31] observed catastrophic failure on the cutting edge during the cryogenic cutting of Inconel 718 when comparing it with dry, MQL and CryoMQL conditions.

By increasing the feed rate to $0.05 \mathrm{~mm} / \mathrm{rev}$, At a higher feed rate of $0.09 \mathrm{~mm} / \mathrm{rev}$, flank wear value dropped significantly to $60 \mu \mathrm{m}$ which was as low as that of flooded cutting, while dry cutting still resulted in high flank wear value of $100 \mu \mathrm{m}$ (Figure 6b). Chipping was still observed under cryogenic cutting at this parameter, but in smaller amount (Figure $8 \mathrm{~b}$ ). Adhesion wear mechanism was promoted at $0.05 \mathrm{~mm} / \mathrm{rev}$ feed rate under cryogenic and flooded conditions which resulted in larger BUE formations (Figure 8 a-d).

Flank wear value did not change significantly compared to that of at $0.05 \mathrm{~mm} / \mathrm{rev}$ (Figure 6b). However, under cryogenic condition, tool wear mechanism changed - chipping was not happened on the major and minor cutting edges under cryogenic cutting (Figure $9 \mathrm{a}, \mathrm{b}$ ), however, another wear mechanism, namely depth of cut (DOC) notch was seen in the minor and major cutting edges. Abrasion and adhesion were other wear mechanisms observed during the cutting of Inconel 718 at different feed rates (Figure 7 Figure 9). Adhesion of workpiece material on the cutting edge was high under cryogenic cutting which resulted in formation of BUE at all the feed rates. Zhuang et al. [39] reported similar results in which high 
adhesion and built-up edge (BUE) were observed in cryogenic cutting of Inconel 718 when comparing the results with plasma-enhanced machining (PEM). Flank wear values were almost the same for cryogenic and flooded conditions at all cutting parameters while dry cutting resulted in higher flank wear at all the cutting parameters.

\subsubsection{Effect of cutting parameters on Ra surface roughness under different cutting conditions}

Figure 10a, b shows variations of Ra surface roughness with cutting speed and feed rate under different cutting conditions. Effect of cutting speed on surface roughness depends on the variation of the cutting force with speed - as cutting speed increased from $20 \mathrm{~m} / \mathrm{min}$ to $70 \mathrm{~m} / \mathrm{min}$, cutting force first decreased to a minimum value $(0.5-0.6 \mu \mathrm{m})$ and increased again at the speed of $120 \mathrm{~m} / \mathrm{min}$ by increasing in the cutting force (Figure 4a).

Figure $10 \mathrm{~b}$ shows that high values of $\mathrm{Ra}(1.65 \mu \mathrm{m})$ were observed at low feed rate $(0.01 \mathrm{~mm} / \mathrm{rev})$ when cutting was carried out using $\mathrm{LN}_{2}$ due to tool failure at this parameter (Figure $7 \mathrm{~b}$ ). Flooded cutting resulted in lower $\mathrm{Ra}(0.32 \mu \mathrm{m})$ at this parameter because cutting force was low (Figure $4 \mathrm{~b})$ and the cutting edge was retained its original shape (Figure 7c, d).

Generally, surface roughness was lower under flooded than cryogenic cutting condition. This can be attributed to brittleness of the workpiece material under cryogenic condition which created more vibration during the cutting process (Figure 5a-c). Similar results were reported by Tebaldo et al. [28]. They compared MQC with dry and flooded cutting and reported that the lowest magnitude of surface roughness when flood turning was obtained compared to cryogenic cutting.

Produced workpiece surface quality under cryogenic and flooded cutting conditions were closely investigated by SEM (Figure 11a, b). Figure 11a shows surface quality produced while $\mathrm{LN}_{2}$ was applied during the cutting process at different feed rates. At low feed rate $(0.01 \mathrm{~mm} / \mathrm{rev})$, at which the tool failed, formation of cavities and high built-up layers (BUL) resulted in high roughness value $(1.7 \mu \mathrm{m})$ and poor surface quality. Side flow and BUL were observed at high feed rate $(0.09 \mathrm{~mm} / \mathrm{rev})$ in lesser extent than $0.01 \mathrm{~mm} / \mathrm{rev}$, but the roughness value was still high $(1.4 \mu \mathrm{m})$. Side flow is the result of high pressure on the workpiece material left behind on the on the secondary cutting edge of the tool [33]. It has been shown that side flow can be zero for brittle materials [40]. At the medium feed rate $(0.05 \mathrm{~mm} / \mathrm{rev})$, however, the surface defects such as groove and BUL were less prominent and the roughness value dropped to $0.6 \mu \mathrm{m}$, resulting in good surface quality, which was comparable to the one produced under flooded cutting as shown in Figure 11b. Under flooded cutting surface quality was consistent whereby there were no dramatic change in formation of surface defects at different cutting parameters like the one happened in cryogenic cutting. However, the surface roughness increased with feed rate (Figure 11b) because of formation of larger feed marks. Therefore, surface quality and formation of surface defects when $\mathrm{LN}_{2}$ was sprayed to the cutting area was highly dependent on the feed rate at which the machining process was carried out. On the opposite, there was a consistency in formation of surface defects under flooded cutting at various cutting speed and feed rates. 
1.2 Statistical analysis and optimization of cutting parameters in cutting Inconel 718 using $\mathrm{LN}_{2}$ by RSM

Experimental results in section 3.1 indicated that there can be a set of parameters in which machinability of Inconel 718 in terms of tool wear, cutting force and surface quality can be improved without using flooded machining. In order to find the optimum cutting parameters under cryogenic cutting condition response surface methodology (RSM) was utilized. Cutting speed, feed rate and depth of cut were selected as the process parameters (Table 1) and flank wear, cutting force, Ra surface roughness and material removal rate (MRR) were considered as the response parameters for multi-objective optimization process using desirability function. Material removal rate (MRR) is defined as $C c x f x$ ap.

Experimental results of machining of Inconel 718 using $\mathrm{LN}_{2}$ according to RSM experimental design arrangement are summarized in Table 2. The effect of cutting parameters on the response parameters were investigated by 3D surface graphs and statistical analyses such as ANOVA so as to determine the most significant parameters on each response factor.

Table 1 Cutting parameters and their levels

\begin{tabular}{|llllll|}
\hline Cutting Parameters & Level 1 & Level 2 & Level 3 & Level 4 & Level 5 \\
\hline Cutting speed, $V_{c}(\mathrm{~m} / \mathrm{min})$ & 20 & 45 & 70 & 95 & 120 \\
\hline Feed rate, $f(\mathrm{~mm} / \mathrm{rev})$ & 0.05 & 0.10 & 0.15 & 0.20 & 0.25 \\
\hline Depth of cut, $a_{p}(\mathrm{~mm})$ & 0.3 & 0.4 & 0.5 & 0.6 & 0.7 \\
\hline
\end{tabular}

Table 2 Experimental results after machining of Inconel 718 using $\mathrm{LN}_{2}$. 


\begin{tabular}{|c|c|c|c|c|c|c|c|c|}
\hline \multirow{2}{*}{$\begin{array}{l}\text { Test } \\
\text { No. }\end{array}$} & \multirow{2}{*}{$\begin{array}{l}\text { Point } \\
\text { Type* }\end{array}$} & \multicolumn{3}{|c|}{ Cutting parameters } & \multicolumn{4}{|c|}{ Response Parameters } \\
\hline & & $\begin{array}{l}\text { Speed, } V_{c} \\
(\mathrm{~m} / \mathrm{min})\end{array}$ & $\begin{array}{l}\text { Feed, } f \\
(\mathrm{~mm} / \mathrm{rev})\end{array}$ & $\begin{array}{l}\text { Depth of cut, } \\
a_{p}(\mathrm{~mm})\end{array}$ & $\begin{array}{l}\text { Cutting } \\
\text { force, } \\
F_{c}(\mathrm{~N})\end{array}$ & $\begin{array}{l}\text { Flank wear, } \\
V B_{B}(\mu \mathrm{m})\end{array}$ & $\begin{array}{l}\text { Surface } \\
\text { roughness, } \\
\operatorname{Ra}(\mu \mathrm{m})\end{array}$ & $\begin{array}{l}\text { MRR } \\
\left(\mathrm{cm}^{3} / \mathrm{mi}\right. \\
\mathrm{n})\end{array}$ \\
\hline 1 & $\mathrm{C}$ & 70 & 0.05 & 0.5 & 86 & 62 & 0.618 & 1.75 \\
\hline 2 & C & 70 & 0.05 & 0.5 & 89 & 63 & 0.611 & 1.75 \\
\hline 3 & C & 70 & 0.05 & 0.5 & 82 & 59 & 0.614 & 1.75 \\
\hline 4 & C & 70 & 0.05 & 0.5 & 80 & 55 & 0.590 & 1.75 \\
\hline 5 & $\mathrm{C}$ & 70 & 0.05 & 0.5 & 83 & 65 & 0.620 & 1.75 \\
\hline 6 & $\mathrm{C}$ & 70 & 0.05 & 0.5 & 85 & 58 & 0.620 & 1.75 \\
\hline 7 & A & 120 & 0.05 & 0.5 & 122 & 160 & 0.920 & 3.00 \\
\hline 8 & A & 70 & 0.09 & 0.5 & 140 & 67 & 1.189 & 3.15 \\
\hline 9 & A & 70 & 0.05 & 0.7 & 120 & 60 & 1.345 & 2.45 \\
\hline 10 & A & 20 & 0.05 & 0.5 & 108 & 53 & 0.805 & 0.5 \\
\hline 11 & A & 70 & 0.01 & 0.5 & 19 & 210 & 1.199 & 0.35 \\
\hline 12 & A & 70 & 0.05 & 0.3 & 40 & 23 & 0.634 & 1.05 \\
\hline 13 & $\mathrm{~F}$ & 95 & 0.03 & 0.6 & 104 & 125 & 0.536 & 1.71 \\
\hline 14 & F & 95 & 0.07 & 0.6 & 153 & 97 & 1.146 & 3.99 \\
\hline 15 & $\mathrm{~F}$ & 95 & 0.03 & 0.4 & 67 & 100 & 0.363 & 1.14 \\
\hline 16 & $\mathrm{~F}$ & 95 & 0.07 & 0.4 & 104 & 103 & 0.658 & 2.66 \\
\hline 17 & $\mathrm{~F}$ & 45 & 0.03 & 0.6 & 106 & 54 & 0.851 & 0.81 \\
\hline 18 & $\mathrm{~F}$ & 45 & 0.07 & 0.6 & 184 & 58 & 1.176 & 1.89 \\
\hline 19 & $\mathrm{~F}$ & 45 & 0.03 & 0.4 & 66 & 54 & 0.961 & 0.54 \\
\hline 20 & $\mathrm{~F}$ & 45 & 0.07 & 0.4 & 110 & 27 & 0.948 & 1.26 \\
\hline
\end{tabular}

* C: Central point, A: Axial point, F: Factorial point

\subsubsection{Effect of cutting parameters on cutting force}

Quadratic regression model developed for the cutting force is presented in Eq. 1 R2 and R2 -adjusted values of the model were calculated as $88.17 \%$ and $82.69 \%$.

$$
F_{c}=-3.5-2.100 V_{c}+1310 f+174 a_{p}+0.01482 V_{c}{ }^{2}+966 f^{2}+51 a_{p}{ }^{2}
$$

Normal probability plot of the residuals (Figure 12a) and histogram of standardized residuals (Figure 12b) for cutting force show that residuals are distributed normally around zero which shows the adequacy of the developed model.

Analysis of variance (ANOVA) for cutting force is presented in Table 3. In this table, DF is degree of freedom which is one for each parameter, SS is sum of squares which is a statistical technique to determine the variation of data point compared to the line of best fit, MS is mean square which is defined as SS/DF, MSE is mean square of error. F-value is calculated as MS/MSE which is used to determine whether the test is statistically significant, meaning the results are meaningful and not gained by random [41]. For this purpose, probability value (P-value) is calculated. P-value is defined as the smallest level of significance $(a=0.05)$ that would lead to rejection of the null hypothesis which is that the average value of the dependent variable is the same for all groups [35]. In other words, when the P-value of a variable is less than 0.05 , it can be stated with the $95 \%$ of confidence that the variable is statistically significant and when the P-value of a variable is between 0.5 and 0.1 , the variable is considered marginally significant [42]. P-value analysis for the cutting parameters in Table 3 showed that cutting speed ( $P$-value $=0.011$ ) 
was the only statistically significant parameter for cutting force. Feed rate (P-value $=0.122)$ had a marginally significant effect on cutting force.

Table 3 Results of ANOVA for cutting force

\begin{tabular}{llllll}
\hline Source & DF & SS & MS (SS/DF) & F-Value (MS/MSE) & P-Value $(\alpha=0.05)$ \\
\hline Model & 6 & 23025.0 & 3837.50 & 16.13 & 0.000 \\
$V_{c}$ & 1 & 2103.5 & 2103.46 & 8.84 & $0.011^{*}$ \\
$f$ & 1 & 649.2 & 649.20 & 2.73 & 0.122 \\
$a_{p}$ & 1 & 74.8 & 74.83 & 0.31 & 0.584 \\
$V_{c}{ }^{2}$ & 1 & 2156.6 & 2156.57 & 9.06 & $0.010^{*}$ \\
$f^{2}$ & 1 & 3.8 & 3.75 & 0.02 & 0.902 \\
$a_{p}{ }^{2}$ & 1 & 6.6 & 6.57 & 0.03 & 0.871 \\
Error & 13 & 3092.8 & 237.91 & & \\
Total & 19 & 26117.8 & & & \\
\hline
\end{tabular}

* Significant variables

3D surface graph for interaction effect of the cutting parameters is shown in Figure 13a, b. Increase in cutting speed first reduced the cutting force and then increased it. Cutting force constantly increased with increase in feed rate and depth of cut (Figure 13b).

\subsubsection{Effect of cutting parameters on flank wear}

The experimental data were used for developing a quadratic regression model in terms of flank wear using Box-Cox transformation $(\lambda=0)$ which is presented in Eq. 2 .

$$
\begin{aligned}
\ln V B=1.78 & -0.0007 V_{c}-75.0 f+14.10 a_{p}+0.000176 V_{c}^{2}+433 f^{2} \\
& -11.72 a_{p}{ }^{2}+0.099 V_{c} * f-0.0301 V_{c} * a_{p}+30.1 f * a_{p}
\end{aligned}
$$

Coefficient of determination, $\mathrm{R}^{2}$ and $\mathrm{R}^{2}$-adjusted of the model was calculated as $92.17 \%$ and $85.13 \%$ which confirmed the effectiveness of the model. Figure $14 a, b$ shows the normal probability plot of the residuals for flank wear in which the data closely fall on the straight line indicating that the errors are distributed normally [35]. This also can be seen in Figure 14b in which histogram of residuals for flank wear shows distribution around the zero value.

ANOVA for flank wear in Table 4 shows that all the parameters had statistically significant effect on flank wear as the P-values are less than 0.05 . Cutting speed with the P-value of 0.001 for $V c$ and 0.000 for $\mathrm{V}^{2}{ }_{\mathrm{c}}$ was a highly significant variable. In addition, F-values of cutting speed showed that it was the most influential parameter on flank wear.

Table 4 Results of ANOVA for flank wear 


\begin{tabular}{lllllll}
\hline Source & DF & SS & Adj SS & Adj MS (Adj SS/DF) & F-Value (MS/MSE) & P-Value $(\alpha=0.05)$ \\
\hline Model & 9 & 4.76737 & 4.76737 & 0.529708 & 13.08 & 0.000 \\
$V_{c}$ & 1 & 1.90332 & 0.00006 & 0.000062 & 0.00 & 0.970 \\
$f$ & 1 & 0.61253 & 0.43641 & 0.436414 & 10.78 & $0.008^{*}$ \\
$a_{p}$ & 1 & 0.50603 & 0.34274 & 0.342736 & 8.46 & $0.016^{*}$ \\
$V_{c}{ }^{2}$ & 1 & 0.27140 & 0.30279 & 0.302791 & 7.48 & $0.021^{*}$ \\
$f^{2}$ & 1 & 1.03469 & 0.75277 & 0.752775 & 18.59 & $0.002^{*}$ \\
$a_{p}{ }^{2}$ & 1 & 0.34544 & 0.34544 & 0.345439 & 8.53 & $0.015^{*}$ \\
$V_{c} \times f$ & 1 & 0.01977 & 0.01977 & 0.019765 & 0.49 & 0.501 \\
$V_{c} \times a_{p}$ & 1 & 0.04522 & 0.04522 & 0.045222 & 1.12 & 0.315 \\
$f \times a_{p}$ & 1 & 0.02897 & 0.02897 & 0.028974 & 0.72 & 0.417 \\
Error & 10 & 0.40491 & 0.40491 & 0.040491 & & \\
Total & 19 & 5.17229 & & & & \\
\hline
\end{tabular}

*Significant variables

Effect of cutting speed on flank wear also can be observed in Figure 15. Flank wear increased significantly with the cutting speed especially at the lower feed rates and high depth of cuts. At high cutting speed of $120 \mathrm{~m} / \mathrm{min}$, flank wear first decreased to a minimum value of $180 \mu \mathrm{m}$ at the feed rate of $0.06 \mathrm{~mm} / \mathrm{rev}$ and then increased exponentially to $410 \mu \mathrm{m}$.

\subsubsection{Effect of cutting parameters on Ra surface roughness}

Regression model for predicting Ra surface roughness was developed using Box-Cox transformation $(\lambda=2)$ (Eq. 3). Coefficient of determination, R2 and R2- adjusted of the developed model were calculated as $82.52 \%$ and $66.72 \%$.

$$
\begin{aligned}
R a^{2}=9.51- & 0.0486 V_{c}-112.4 f-21.31 a_{p}+0.000126 V_{c}^{2}+622 f^{2} \\
& +16.86 a_{p}{ }^{2}+0.174 V_{c} \times f+0.0376 V_{c} \times a_{p}+88.0 f \times a_{p}
\end{aligned}
$$

Normal probability plot (Figure 16a) and histogram of standardized residual (Figure 16b) showed that the residuals were distributed around zero which confirmed that the developed model was adequate. F-values and P-values of feed rate and depth of cut presented in Table 5 showed that these parameters were statistically significant for Ra surface roughness.

Table 5 Results of ANOVA for Ra surface roughness 


\begin{tabular}{lllllll}
\hline Source & DF SS & Adj SS & Adj MS (Adj SS/DF) & F-Value (MS/MSE) & P-Value $(\alpha=0.05)$ \\
\hline Model & 9 & 3.69923 & 3.69923 & 0.41103 & 5.25 & 0.008 \\
$V_{c}$ & 1 & 0.11674 & 0.28313 & 0.28313 & 3.61 & 0.086 \\
$f$ & 1 & 0.22828 & 0.97885 & 0.97885 & 12.49 & $0.005^{*}$ \\
$a_{p}$ & 1 & 1.06906 & 0.78273 & 0.78273 & 9.99 & $0.010^{*}$ \\
$V_{c}{ }^{2}$ & 1 & 0.00080 & 0.15712 & 0.15712 & 2.01 & 0.187 \\
$f^{2}$ & 1 & 1.19034 & 1.55467 & 1.55467 & 19.84 & $0.001^{*}$ \\
$a_{p}{ }^{2}$ & 1 & 0.71488 & 0.71488 & 0.71488 & 9.12 & $0.013^{*}$ \\
$V_{c} \times f$ & 1 & 0.06056 & 0.06056 & 0.06056 & 0.77 & 0.400 \\
$V_{c} \times a_{p}$ & 1 & 0.07058 & 0.07058 & 0.07058 & 0.90 & 0.365 \\
$f \times a_{p}$ & 1 & 0.24799 & 0.24799 & 0.24799 & 3.17 & 0.106 \\
Error & 10 & 0.40491 & 0.40491 & 0.040491 & & \\
Total & 19 & 5.17229 & & & & \\
\hline
\end{tabular}

* Significant variables

Figure 17a shows the variation of Ra surface roughness with cutting speed and feed rate. At low feed rates, Ra values were high $(1.4 \mu \mathrm{m})$ which was because of high tool wear as a result of chipping (Figure 7). However, by increasing the feed rate, Ra decreased to a minimum value and then increased again with higher feed rates. Higher feed rates result in higher feed marks on the machined surface (Figure 11). Ra surface roughness increased with increasing depth of cut due to generation of deeper feed marks especially at high feed rate of $0.09 \mathrm{~mm} / \mathrm{rev}$ (Figure 17b). Minimum amount of Ra roughness was achieved at cutting speed of $90 \mathrm{~m} / \mathrm{min}$, feed rate of $0.04 \mathrm{~mm} / \mathrm{rev}$ and $0.4 \mathrm{~mm}$ depth of cut.

\subsubsection{Multi-objective optimization}

Desirability function of RSM was used to perform the multi-objective optimization in order to find the optimal cutting parameters that would result in the maximum possible material removal rate, while maintaining the lowest possible flank wear, cutting force and Ra surface roughness values. Each response parameter was converted to a desirability function varying from 0 to 1 in which zero means the response is outside the acceptable region and the value of one indicates that the response has reached the goal. Individual desirability was combined to provide a measure of composite desirability of the multi response system [16]. Constraints for optimizing flank wear, surface roughness, cutting force and material removal rate are summarized in Table 6. It was determined that cutting speed of $87 \mathrm{~m} / \mathrm{min}$, feed rate of $0.06 \mathrm{~m} / \mathrm{rev}$ and depth of cut of $0.37 \mathrm{~mm}$ were the optimum cutting parameters for achieving flank wear of $58 \mu \mathrm{m}$, cutting force of $78 \mathrm{~N}$ and Ra surface roughness of $0.49 \mu \mathrm{m}$ with the MRR value of 1.97 $\mathrm{cm}^{3} / \min$ (Table 7).

The proposed ranges for the cutting parameters which was provided by the manufacturer were cutting speed of $40 \mathrm{~m} / \mathrm{min}(0.08-3)$, feed rate of $0.04 \mathrm{~mm} / \mathrm{rev}(0.02-0.1)$ and depth of cut of 0.2 (0.08-3). The optimum feed rate and depth of cut found in this research are in the range of the manufacturer's catalogue, but the cutting speed is twice as high as the one that manufacturer was proposed which means higher production rate can be possible. 
Table 6 Constraints for optimization of flank wear, surface roughness, cutting force and material removal rate

\begin{tabular}{lllllll} 
removal rate & \multicolumn{1}{l}{ Goal } & Lower & Target & Upper & Weight & Importance \\
\hline Response & Minimum & - & 19 & 184 & 1 & 1 \\
Cutting force, $F_{c}(\mathrm{~N})$ & Minimum & - & 23 & 210 & 1 & 1 \\
Flank wear, $V B_{B}(\mu \mathrm{m})$ & Minimum & - & 0.363 & 1.345 & 1 & 1 \\
Surface roughness, $\mathrm{Ra}(\mu \mathrm{m})$ & Maximum & 0.35 & 3.99 & - & 1 & 1 \\
$M R R\left(\mathrm{~cm}^{3} / \mathrm{min}\right)$ & & & & &
\end{tabular}

Table 7 Multi-objective optimization results for response parameters

\begin{tabular}{|c|c|c|c|c|c|c|c|}
\hline \multirow{2}{*}{$\begin{array}{l}\text { Cutting } \\
\text { speed, } V_{c}\end{array}$} & \multirow{2}{*}{$\begin{array}{l}\text { Feed } \\
\text { rate, } f\end{array}$} & \multirow{2}{*}{$\begin{array}{l}\text { Depth of } \\
\text { cut, } a_{p}\end{array}$} & \multirow{2}{*}{$\begin{array}{l}\text { Composite } \\
\text { Desirability }\end{array}$} & \multicolumn{4}{|c|}{ Predicted values } \\
\hline & & & & $\begin{array}{l}\text { Cutting } \\
\text { force, } \\
F_{c}(\mathrm{~N})\end{array}$ & $\begin{array}{l}\text { Flank wear, } \\
V B_{B}(\mu \mathrm{m})\end{array}$ & $\begin{array}{l}\text { Surface } \\
\text { roughness, } \\
\operatorname{Ra}(\mu \mathrm{m})\end{array}$ & $\begin{array}{l}M R R \\
\left(\mathrm{~cm}^{3} / \mathrm{min}\right)\end{array}$ \\
\hline 87 & 0.06 & 0.37 & 0.68 & 78 & 58 & 0.49 & 1.97 \\
\hline
\end{tabular}

\section{Summary And Conclusions}

In this work, effect of cryogenic turning on Inconel 718 was experimentally investigated by determining the flank wear, cutting force and Ra surface roughness at different cutting speeds and feed rates and comparing them with those obtained from flooded and dry conditions. The experimental results showed that the machining behaviour of Inconel 718 under cryogenic cutting was highly dependent on the cutting parameters and the cryogenic cutting performance of Inconel 718, in terms of cutting force, flank wear and surface roughness, was inferior to that of the flooded cutting in most of the cases. It was also shown that using 'medium cutting parameters', the cutting performance was as good as flooded cutting showing low flank wear and low surface roughness $(\mathrm{Ra})$ comparable to flooded condition. Desirability function of response surface methodology (RSM) was employed to determine the set of cryogenic cutting parameters that provided the lowest cutting force together with the lowest flank wear and Ra that can be achieved while maintaining the highest material removal rate (MRR). Analysis of variance (ANOVA) was employed to determine the significant factors affecting the response parameters. Following are the main results drawn from this research:

1. Application of liquid nitrogen spray to the cutting area lowered the flank wear compared to dry cutting, resulting in the values as low as the ones from flooded cutting. Abrasion of flank face of the tool and adhesion of Inconel 718 material, which resulted in high BUE formation on the cutting edge, were the wear mechanisms in cryogenic, flooded and dry conditions. Chipping and depth-of-cut notch were observed at low $(0.01 \mathrm{~mm} / \mathrm{rev})$ and high $(0.09 \mathrm{~mm} / \mathrm{rev})$ feed rates under cryogenic condition.

2. Ra surface roughness was higher in cryogenic cutting than in flooded cutting at all the cutting parameters due to higher cutting tool vibrations during the cutting under cryogenic condition. 
Formation of surface defects such as built-up layers and cavities during cutting using $\mathrm{LN}_{2}$ was dependent on the value of cutting speed and feed rate, as opposed to flooded cutting during which there was a consistency in the obtained surface quality. Surface produced at the medium feed rate $(0.05 \mathrm{~mm} / \mathrm{rev})$ was comparable to that of flooded cutting.

3. Multi-objective optimization using desirability function of RSM showed that a cutting speed of 87 $\mathrm{m} / \mathrm{min}$, a feed rate of $0.06 \mathrm{~mm} / \mathrm{rev}$ and a depth of cut of $0.68 \mathrm{~mm}$ would constitute an optimum set of cutting parameters for achieving the lowest possible flank wear $(58 \mu \mathrm{m})$, cutting force $(78 \mathrm{~N})$ and Ra surface roughness $(0.49 \mu \mathrm{m})$ and the highest possible MRR $\left(1.97 \mathrm{~cm}^{3} / \mathrm{min}\right)$ in cryogenic cutting under the current test condition.

\section{Declarations}

Funding: This research was supported by the Natural Sciences and Engineering Research Council of Canada (NSERC) under the CANRIMT Strategic Research Network Grant NETGP 479639- 15.

Availability of data and material: Not applicable.

Code availability: Not applicable.

Competing interests: The authors declare no competing interests.

\section{References}

1. Donachie MJ, Donachie SJ (2002) Superalloys: a technical guide. ASM international,

2. Eskandari B, Davoodi B, Ghorbani H (2018) Multi-objective optimization of parameters in turning of N155 iron-nickel-base superalloy using gray relational analysis. Journal of the Brazilian Society of Mechanical Sciences and Engineering 40 (4):233. doi:10.1007/s40430-018-1156-y

3. Zhu D, Zhang X, Ding H (2013) Tool wear characteristics in machining of nickel-based superalloys. International Journal of Machine Tools and Manufacture 64:60-77. doi:https://doi.org/10.1016/j.ijmachtools.2012.08.001

4. Debnath S, Reddy MM, Yi QS (2016) Influence of cutting fluid conditions and cutting parameters on surface roughness and tool wear in turning process using Taguchi method. Measurement 78:111-119. doi:https://doi.org/10.1016/j.measurement.2015.09.011

5. Davoodi B, Eskandari B (2019) Evaluation of surface damage mechanisms and optimisation of cutting parameters in turning of N-155 iron-nickel-base superalloy. International Journal of Machining and Machinability of Materials 21 (1-2):100-114

6. Thakur A, Gangopadhyay S (2016) State-of-the-art in surface integrity in machining of nickel-based super alloys. International Journal of Machine Tools and Manufacture 100:25-54. 
doi:https://doi.org/10.1016/j.ijmachtools.2015.10.001

7. Ezugwu EO, Bonney J (2004) Effect of high-pressure coolant supply when machining nickel-base, Inconel 718, alloy with coated carbide tools. Journal of Materials Processing Technology 153-154:10451050. doi:https://doi.org/10.1016/j.jmatprotec.2004.04.329

8. Hegab H, Umer U, Soliman M, Kishawy HA (2018) Effects of nano-cutting fluids on tool performance and chip morphology during machining Inconel 718. The International Journal of Advanced Manufacturing Technology 96 (9):3449-3458. doi:10.1007/s00170-018-1825-0

9. Azhdari Tadavani S, Shoja Razavi R, Vafaei R (2017) Pulsed laser-assisted machining of Inconel 718 superalloy. Optics \& Laser Technology 87:72-78. doi:https://doi.org/10.1016/j.optlastec.2016.07.020

10. Parida AK, Maity K (2019) Numerical and experimental analysis of specific cutting energy in hot turning of Inconel 718. Measurement 133:361-369.

doi:https://doi.org/10.1016/j.measurement.2018.10.033

11. Parida AK, Maity K (2021) Study of machinability in heat-assisted machining of nickel-base alloy. Measurement 170:108682. doi:https://doi.org/10.1016/j.measurement.2020.108682

12. Bai W, Bisht A, Roy A, Suwas S, Sun R, Silberschmidt VV (2019) Improvements of machinability of aerospace-grade Inconel alloys with ultrasonically assisted hybrid machining. The International Journal of Advanced Manufacturing Technology 101 (5):1143-1156. doi:10.1007/s00170-018-3012-8

13. Khuri Al, Mukhopadhyay S (2010) Response surface methodology. Wiley Interdisciplinary Reviews: Computational Statistics 2 (2):128-149

14. Koyee RD, Heisel U, Eisseler R, Schmauder S (2014) Modeling and optimization of turning duplex stainless steels. Journal of Manufacturing Processes 16 (4):451-467.

doi:https://doi.org/10.1016/j.jmapro.2014.05.004

15. Sivalingam V, Zhao Y, Thulasiram R, Sun J, kai G, Nagamalai T (2021) Machining Behaviour, surface integrity and tool wear analysis in environment friendly turning of Inconel 718 alloy. Measurement 174:109028. doi:https://doi.org/10.1016/j.measurement.2021.109028

16. Davoodi B, Eskandari B (2015) Tool wear mechanisms and multi-response optimization of tool life and volume of material removed in turning of $\mathrm{N}-155$ iron-nickel-base superalloy using RSM. Measurement 68:286-294. doi:https://doi.org/10.1016/j.measurement.2015.03.006

17. Günay M, Korkmaz ME, Yaşar N (2020) Performance analysis of coated carbide tool in turning of Nimonic $80 \mathrm{~A}$ superalloy under different cutting environments. Journal of Manufacturing Processes 56:678-687. doi:https://doi.org/10.1016/j.jmapro.2020.05.031 
18. Zhang P, Liu Z, Du J, Su G, Zhang J, Xu C (2020) On machinability and surface integrity in subsequent machining of additively-manufactured thick coatings: A review. Journal of Manufacturing Processes 53:123-143. doi:https://doi.org/10.1016/j.jmapro.2020.02.013

19. Shaw M, Smith $P$ (1956) Methods of applying cutting fluids. American Society of Tool and Manufacturing Engineers (ASTME)

20. Krishnamurthy G, Bhowmick S, Altenhof W, Alpas AT (2017) Increasing efficiency of Ti-alloy machining by cryogenic cooling and using ethanol in MRF. CIRP Journal of Manufacturing Science and Technology 18:159-172. doi:https://doi.org/10.1016/j.cirpj.2017.01.001

21. Yildiz Y, Nalbant M (2008) A review of cryogenic cooling in machining processes. International Journal of Machine Tools and Manufacture 48 (9):947-964.

doi:https://doi.org/10.1016/j.ijmachtools.2008.01.008

22. Pusavec F, Hamdi H, Kopac J, Jawahir IS (2011) Surface integrity in cryogenic machining of nickel based alloy-Inconel 718. Journal of Materials Processing Technology 211 (4):773-783. doi:https://doi.org/10.1016/j.jmatprotec.2010.12.013

23. Hong SY, Zhao Z (1999) Thermal aspects, material considerations and cooling strategies in cryogenic machining. Clean Products and Processes 1 (2):107-116. doi:10.1007/s100980050016

24. Hong SY, Ding Y, Jeong J (2002) Experimental evaluation of friction coefficient and liquid nitrogen lubrication effect in cryogenic machining. Machining Science and Technology 6 (2):235-250. doi:10.1081/MST-120005958

25. Kaynak Y (2014) Evaluation of machining performance in cryogenic machining of Inconel 718 and comparison with dry and MQL machining. The International Journal of Advanced Manufacturing Technology 72 (5):919-933. doi:10.1007/s00170-014-5683-0

26. Stephenson DA, Skerlos SJ, King AS, Supekar SD (2014) Rough turning Inconel 750 with supercritical CO2-based minimum quantity lubrication. Journal of Materials Processing Technology 214 (3):673-680. doi:https://doi.org/10.1016/j.jmatprotec.2013.10.003

27. Iturbe A, Hormaetxe E, Garay A, Arrazola PJ (2016) Surface Integrity Analysis when Machining Inconel 718 with Conventional and Cryogenic Cooling. Procedia CIRP 45:67-70. doi:https://doi.org/10.1016/j.procir.2016.02.095

28. Tebaldo V, di Confiengo GG, Faga MG (2017) Sustainability in machining: "Eco-friendly" turning of Inconel 718. Surface characterisation and economic analysis. Journal of Cleaner Production 140:15671577. doi:https://doi.org/10.1016/j.jclepro.2016.09.216

29. Musavi SH, Davoodi B, Eskandari B (2020) Evaluation of surface roughness and optimization of cutting parameters in turning of AA2024 alloy under different cooling-lubrication conditions using RSM 
method. Journal of Central South University 27 (6):1714-1728. doi:10.1007/s11771-020-4402-2

30. Shokrani A, Dhokia V, Newman ST (2016) Investigation of the effects of cryogenic machining on surface integrity in CNC end milling of Ti-6Al-4V titanium alloy. Journal of Manufacturing Processes 21:172-179. doi:https://doi.org/10.1016/j.jmapro.2015.12.002

31. Pusavec F, Deshpande A, Yang S, M'Saoubi R, Kopac J, Dillon OW, Jawahir IS (2014) Sustainable machining of high temperature Nickel alloy - Inconel 718: part 1 - predictive performance models. Journal of Cleaner Production 81:255-269. doi:https://doi.org/10.1016/j.jclepro.2014.06.040

32. Sharman ARC, Hughes JI, Ridgway K (2015) The effect of tool nose radius on surface integrity and residual stresses when turning Inconel 718 ${ }^{\mathrm{TM}}$. Journal of Materials Processing Technology 216:123-132. doi:https://doi.org/10.1016/j.jmatprotec.2014.09.002

33. Shaw MC, Cookson J (2005) Metal cutting principles, vol 2. Oxford university press New York, 34. Tool-life testing with single-point turning tools (1993-11-15). International Standard ISO 3685 35. Montgomery DC (2017) Design and analysis of experiments. John wiley \& sons, 36. Pawade RS, Sonawane HA, Joshi SS (2009) An analytical model to predict specific shear energy in high-speed turning of Inconel 718. International Journal of Machine Tools and Manufacture 49 (12):979990. doi:https://doi.org/10.1016/j.ijmachtools.2009.06.007

37. Iturbe A, Giraud E, Hormaetxe E, Garay A, Germain G, Ostolaza K, Arrazola PJ (2017) Mechanical characterization and modelling of Inconel 718 material behavior for machining process assessment. Materials Science and Engineering: A 682:441-453. doi:https://doi.org/10.1016/j.msea.2016.11.054

38. Trent EM, Wright PK (2000) Metal cutting. Butterworth-Heinemann, USA

39. Zhuang K, Zhang X, Zhu D, Ding H (2015) Employing preheating- and cooling-assisted technologies in machining of Inconel 718 with ceramic cutting tools: towards reducing tool wear and improving surface integrity. The International Journal of Advanced Manufacturing Technology 80 (9):1815-1822. doi:10.1007/s00170-015-7153-8

40. Sata T, Shaw M (1964) Behavior of cellular materials undergoing plastic flow. CIRP Annals 12:190 41. Archdeacon TJ (1994) Correlation and regression analysis: a historian's guide. Univ of Wisconsin Press,

42. Pritschet L, Powell D, Horne Z (2016) Marginally Significant Effects as Evidence for Hypotheses: Changing Attitudes Over Four Decades. Psychological Science 27 (7):1036-1042. doi:10.1177/0956797616645672 


\section{Figures}

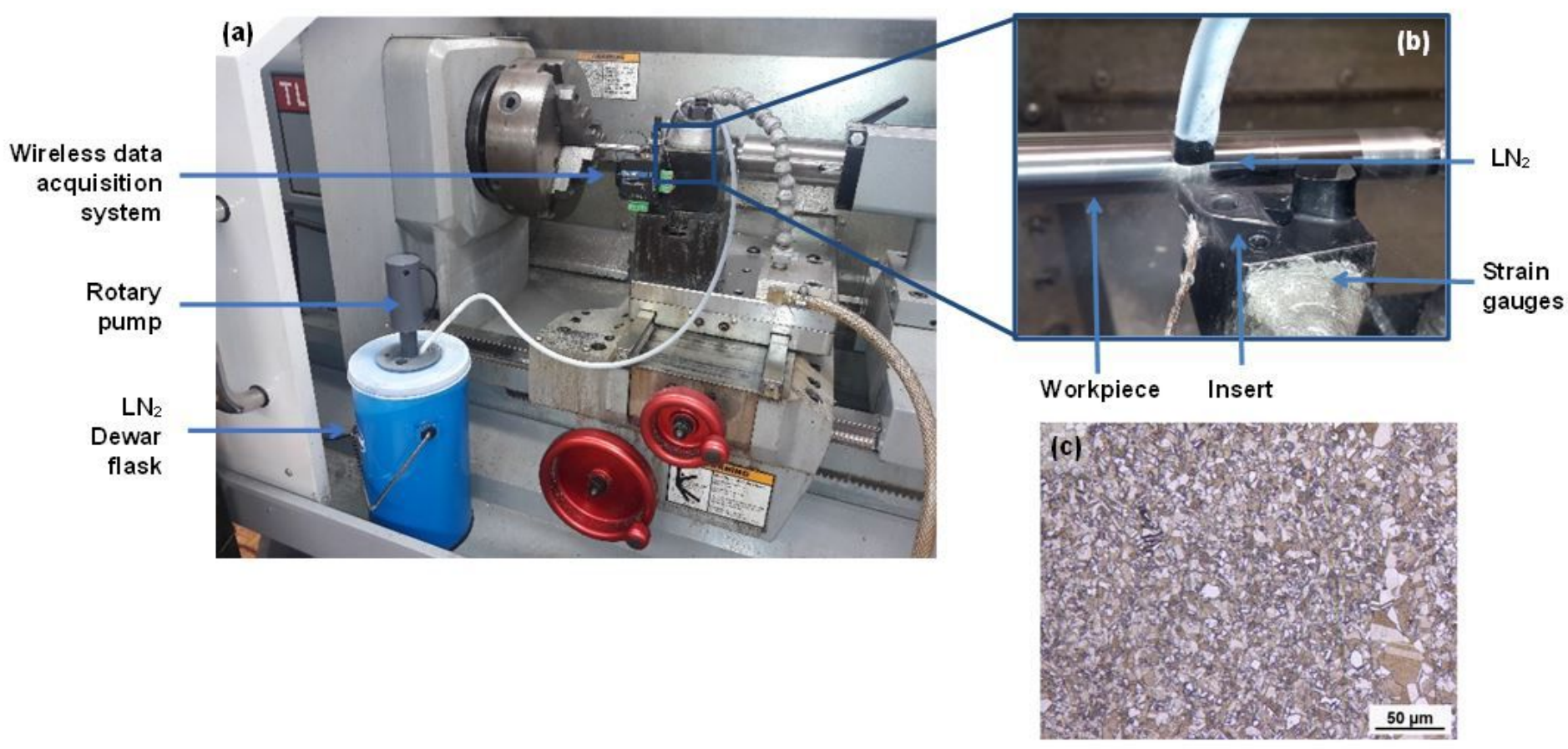

\section{Figure 1}

(a) Experimental setup showing the LN2 Dewar flask, rotary pump and wireless data acquisition system,

(b) application of LN2 to the cutting area, (c) Microstructure of Inconel 718 workpiece. 
(a)

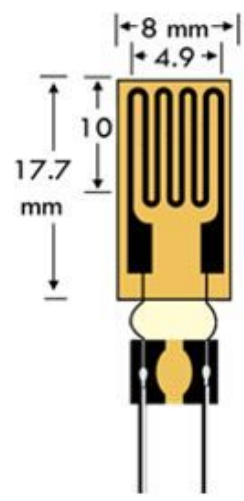

(c)

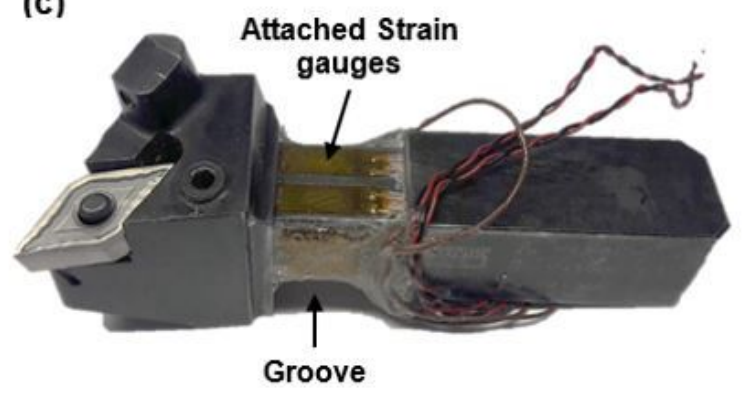

(b)

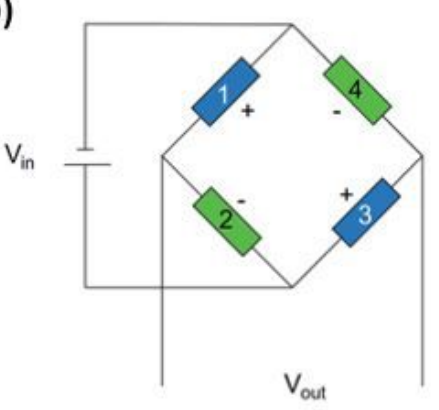

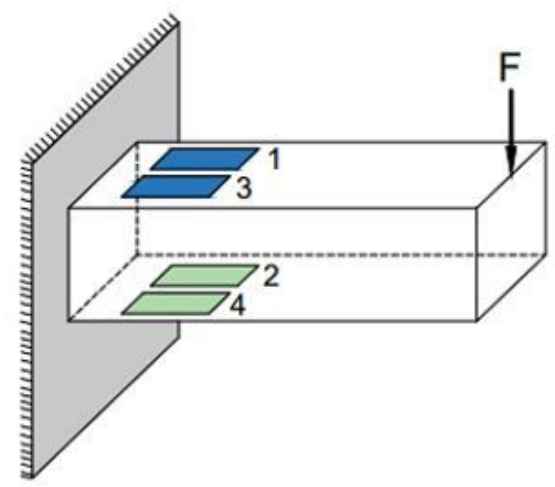

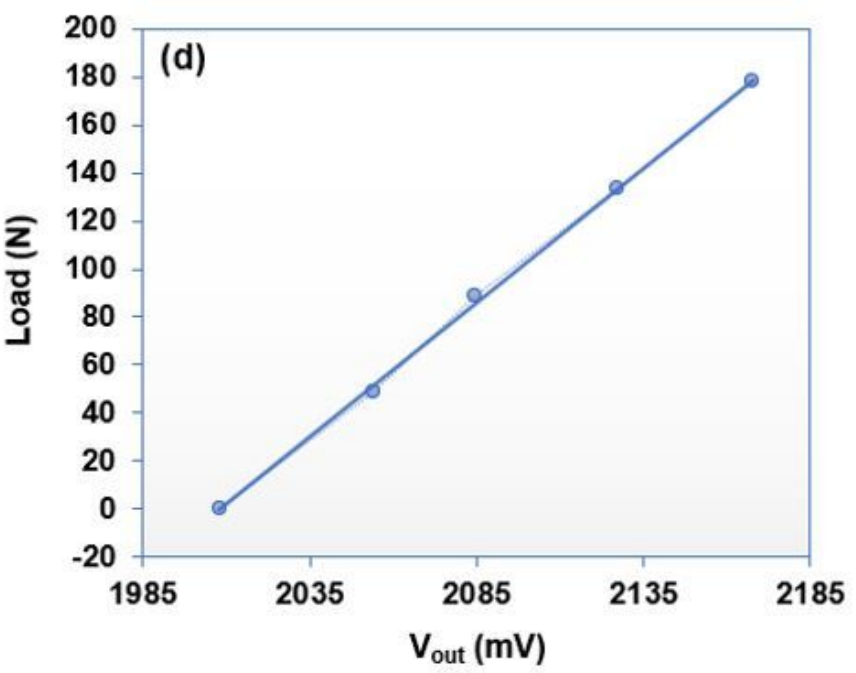

Figure 2

(a) Dimensions of linear strain gauge, (b) Wheatstone bridge configuration on the tool holder, (c) strain gauges attached on the tool holder, (d) calibration diagram, the obtained equation is Load $=1.1209 \mathrm{x}$ Vout - 2251. 


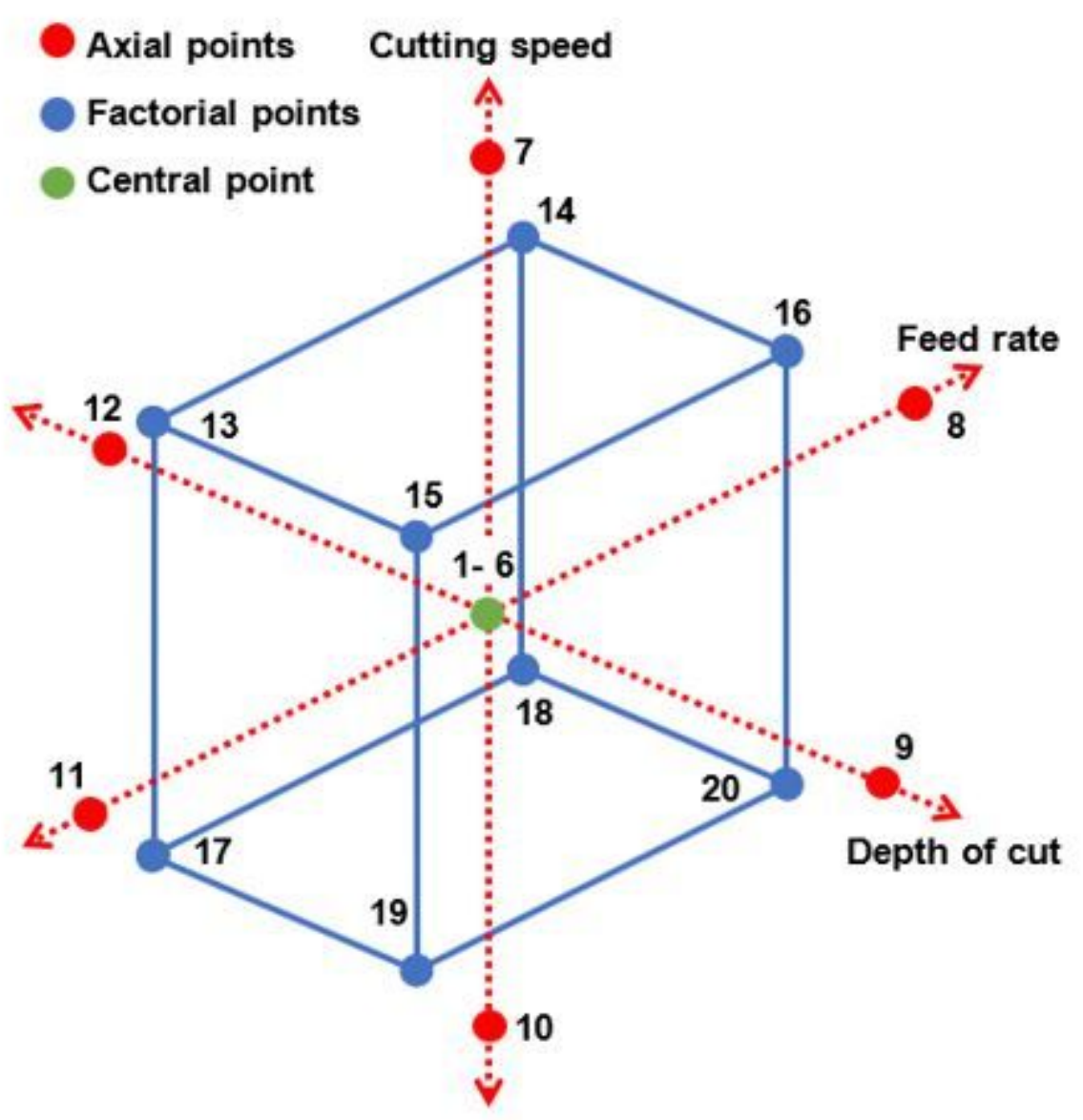

Figure 3

RSM design of experiments cube plot with the test numbers. 

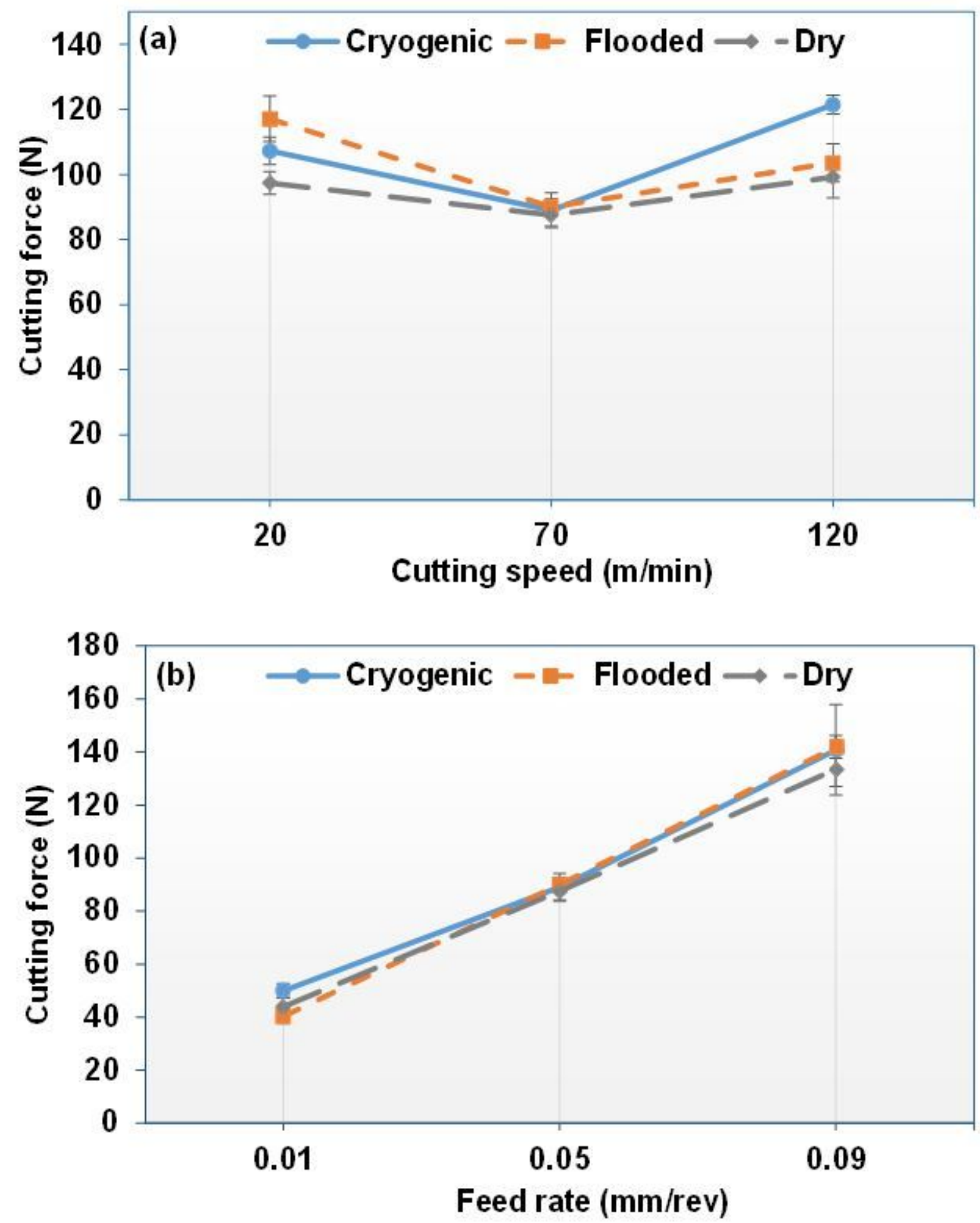

Figure 4

Cutting force values at different (a) cutting speeds $(f=0.05 \mathrm{~mm} / \mathrm{rev}, \mathrm{ap}=0.5 \mathrm{~mm})$, (b) feed rates $(\mathrm{Vc}=70$ $\mathrm{m} / \mathrm{min}$, ap $=0.5 \mathrm{~mm}$ ) under cryogenic, flooded and dry conditions. 

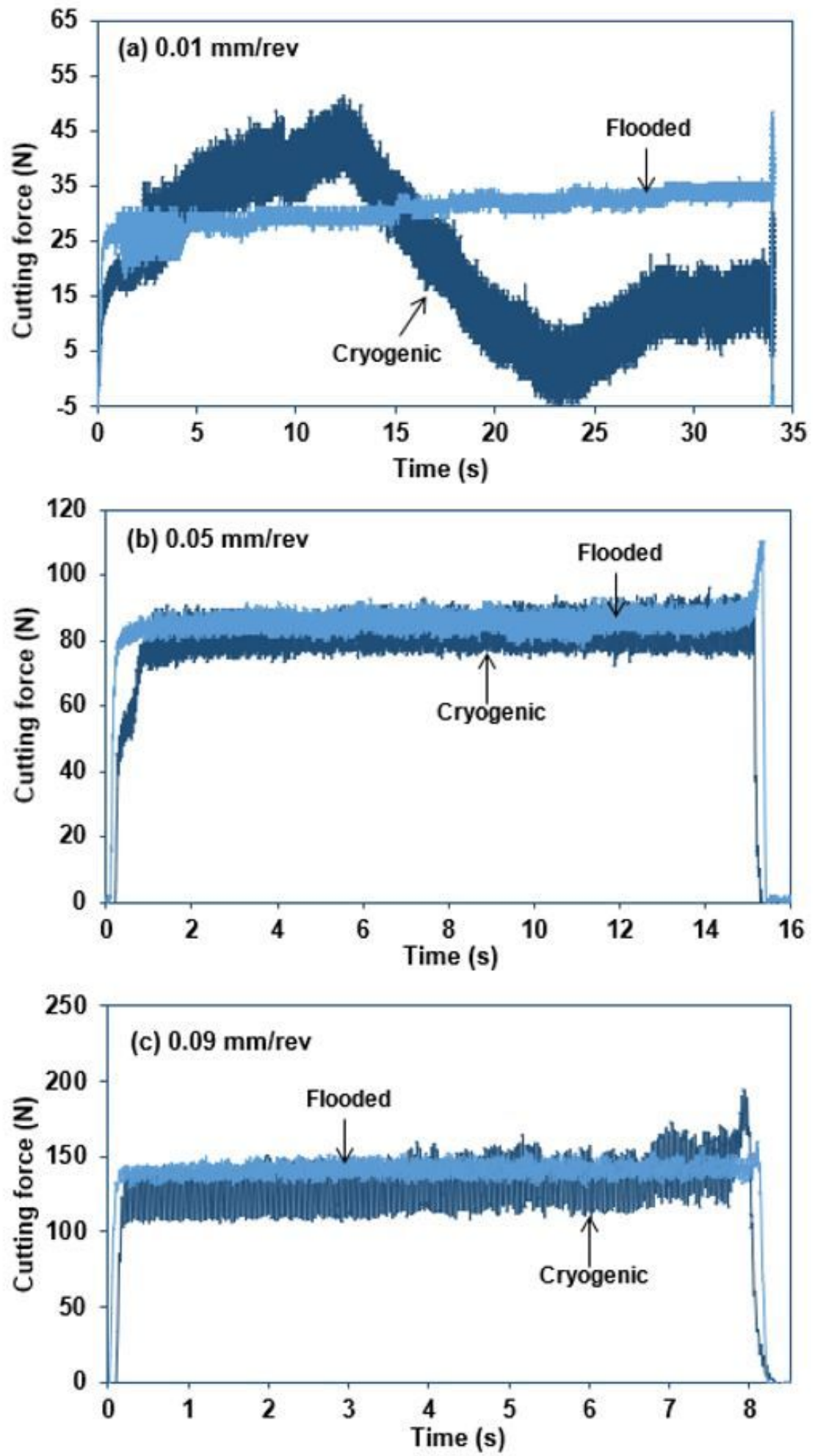

Figure 5

Variation of cutting force with time at feed rate of (a) $0.01 \mathrm{~mm} / \mathrm{rev}$, (b) $0.05 \mathrm{~mm} / \mathrm{rev}$ and (c) $0.09 \mathrm{~mm} / \mathrm{rev}$ when LN2 is applied to the cutting area. 

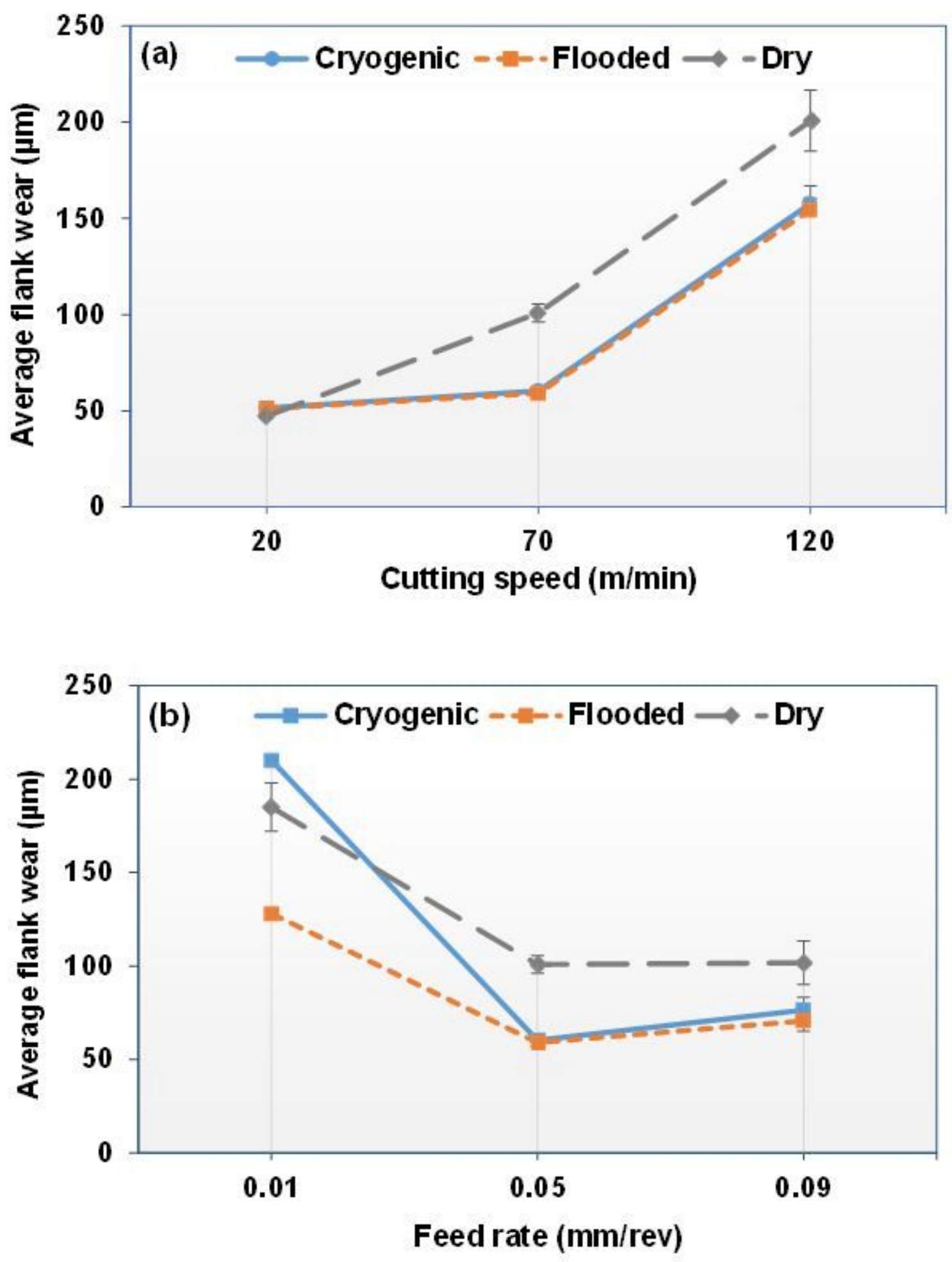

Figure 6

Average flank wear values at different (a) cutting speeds ( $f=0.05 \mathrm{~mm} / \mathrm{rev}$, ap $=0.5 \mathrm{~mm}$ ), (b) feed rates $(\mathrm{Vc}=70 \mathrm{~m} / \mathrm{min}$, ap $=0.5 \mathrm{~mm})$ under cryogenic, flooded and dry conditions. 

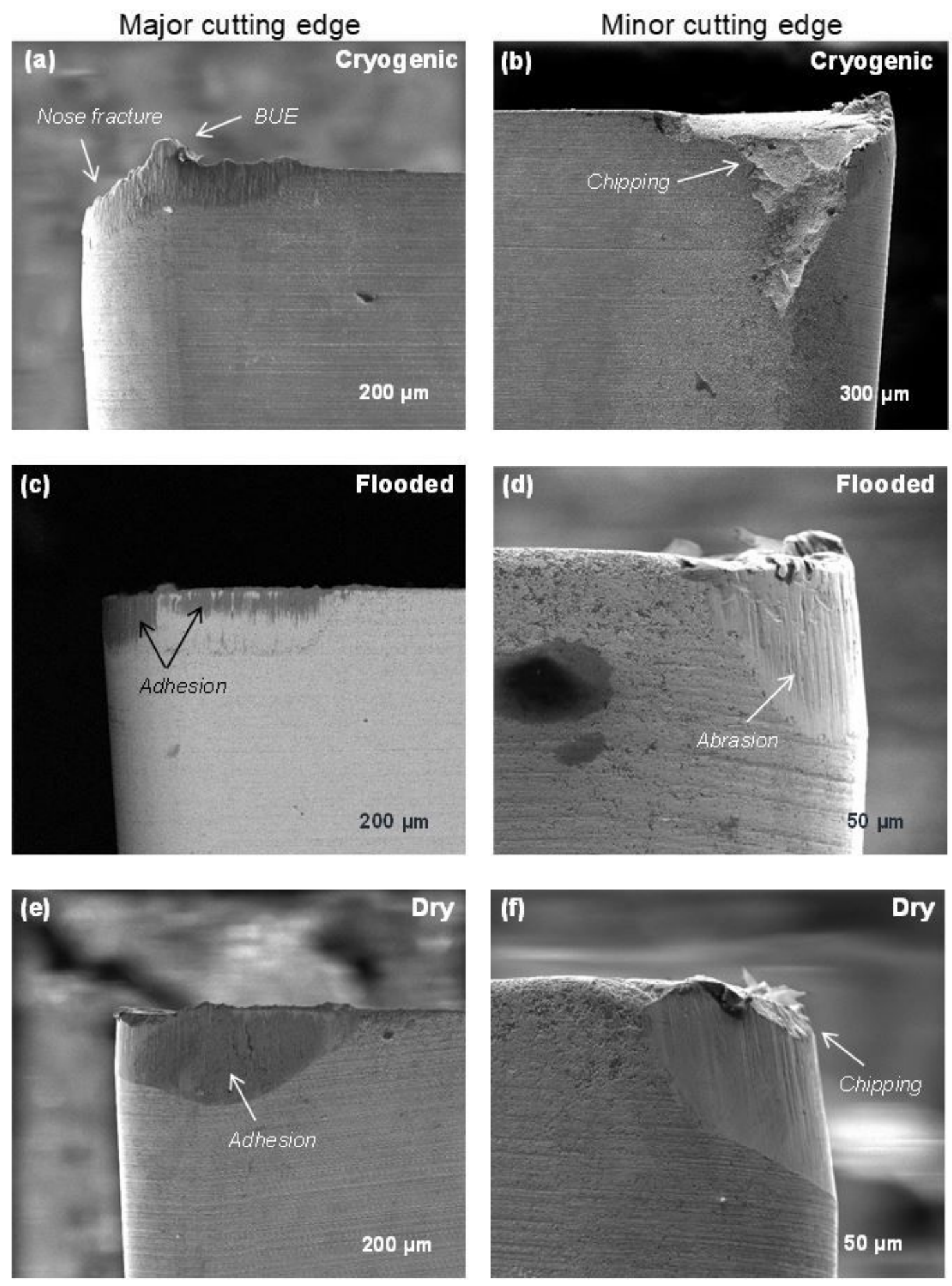

\section{Figure 7}

SEM images of tool cutting edge at feed rate of $0.01 \mathrm{~mm} / \mathrm{rev}$, cutting speed of $70 \mathrm{~m} / \mathrm{min}$ and depth of cut of $0.5 \mathrm{~mm}$ under $(\mathrm{a}, \mathrm{b})$ cryogenic, $(\mathrm{c}, \mathrm{d})$ flooded and $(\mathrm{e}, \mathrm{f})$ dry cutting conditions. 

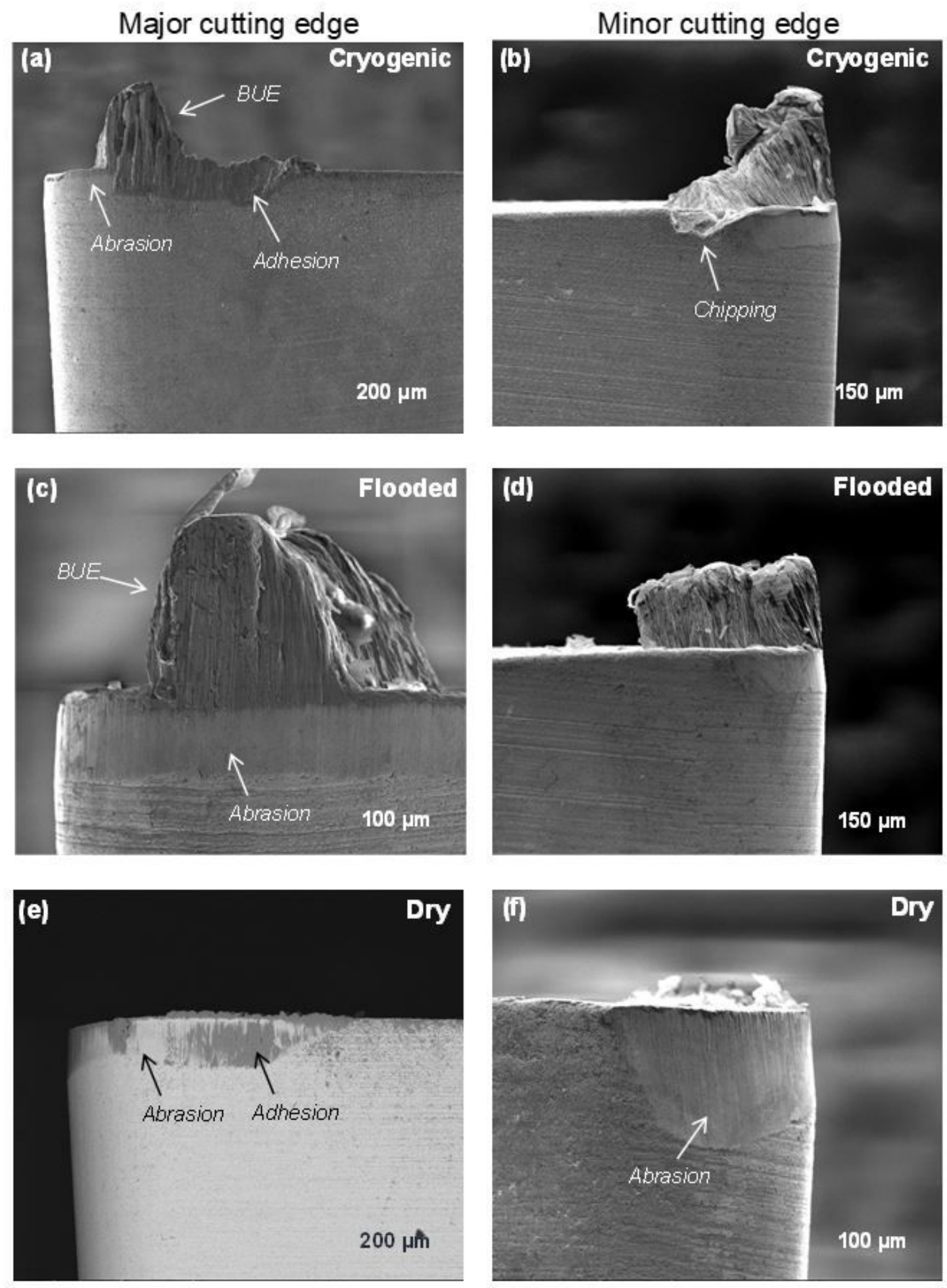

\section{Figure 8}

SEM images of tool cutting edge at feed rate of $0.05 \mathrm{~mm} / \mathrm{rev}$, cutting speed of $70 \mathrm{~m} / \mathrm{min}$ and depth of cut of $0.5 \mathrm{~mm}$ under $(\mathrm{a}, \mathrm{b})$ cryogenic, $(\mathrm{c}, \mathrm{d})$ flooded and $(\mathrm{e}, \mathrm{f})$ dry cutting conditions. 
Major cutting edge
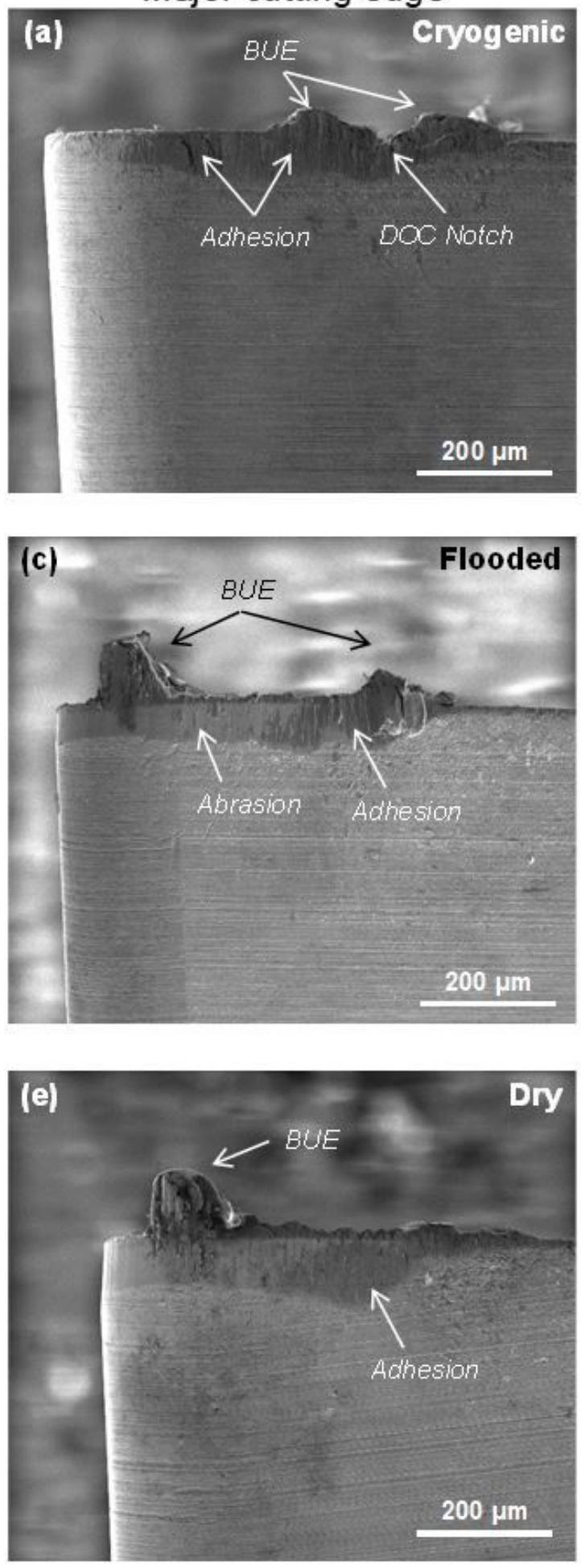

Minor cutting edge
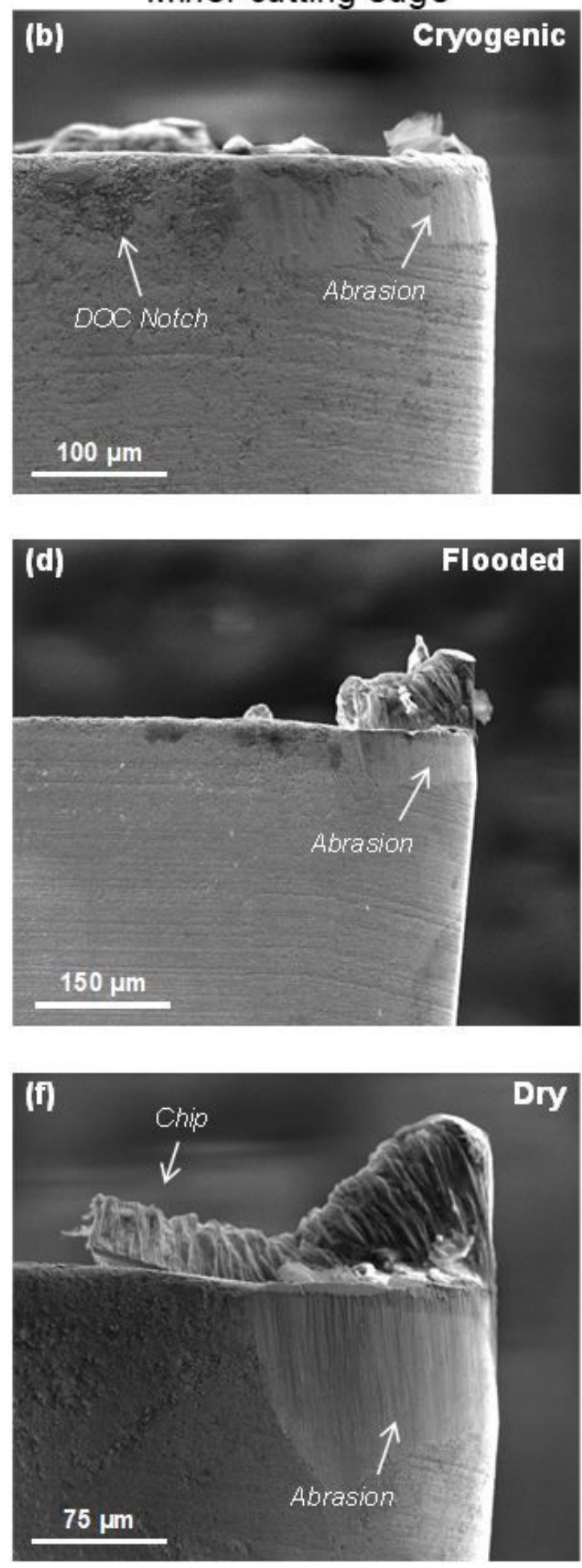

\section{Figure 9}

SEM images of tool cutting edge at feed rate of $0.09 \mathrm{~mm} / \mathrm{rev}$, cutting speed of $70 \mathrm{~m} / \mathrm{min}$ and depth of cut of $0.5 \mathrm{~mm}$ under $(\mathrm{a}, \mathrm{b})$ cryogenic, $(\mathrm{c}, \mathrm{d})$ flooded and $(\mathrm{e}, \mathrm{f})$ dry cutting conditions. 

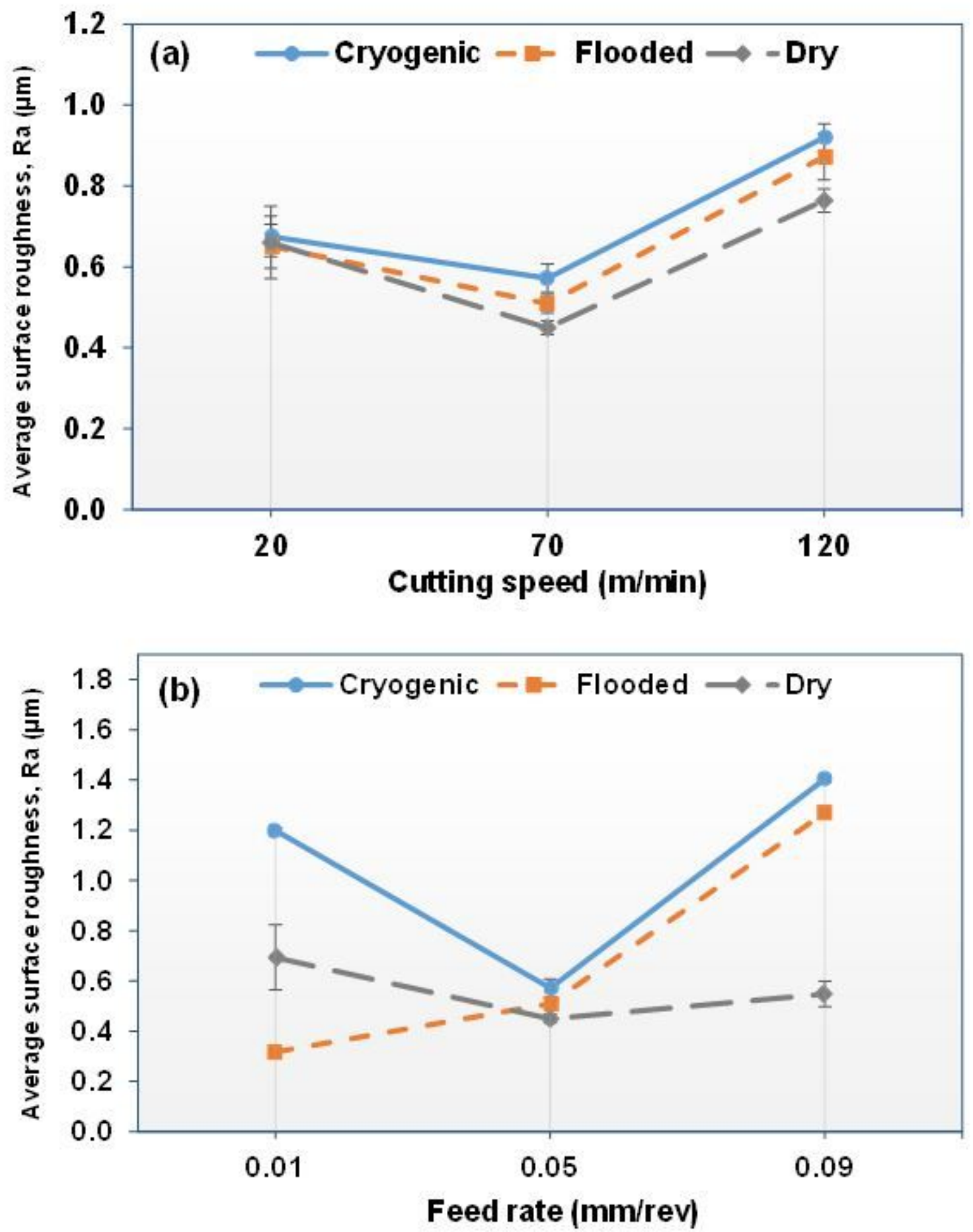

Figure 10

Average Ra surface roughness values at different (a) cutting speeds ( $f=0.05 \mathrm{~mm} / \mathrm{rev}$, ap $=0.5 \mathrm{~mm})$, (b) feed rates $(\mathrm{Vc}=70 \mathrm{~m} / \mathrm{min}$, ap $=0.5 \mathrm{~mm})$ under cryogenic, flooded and dry conditions. 

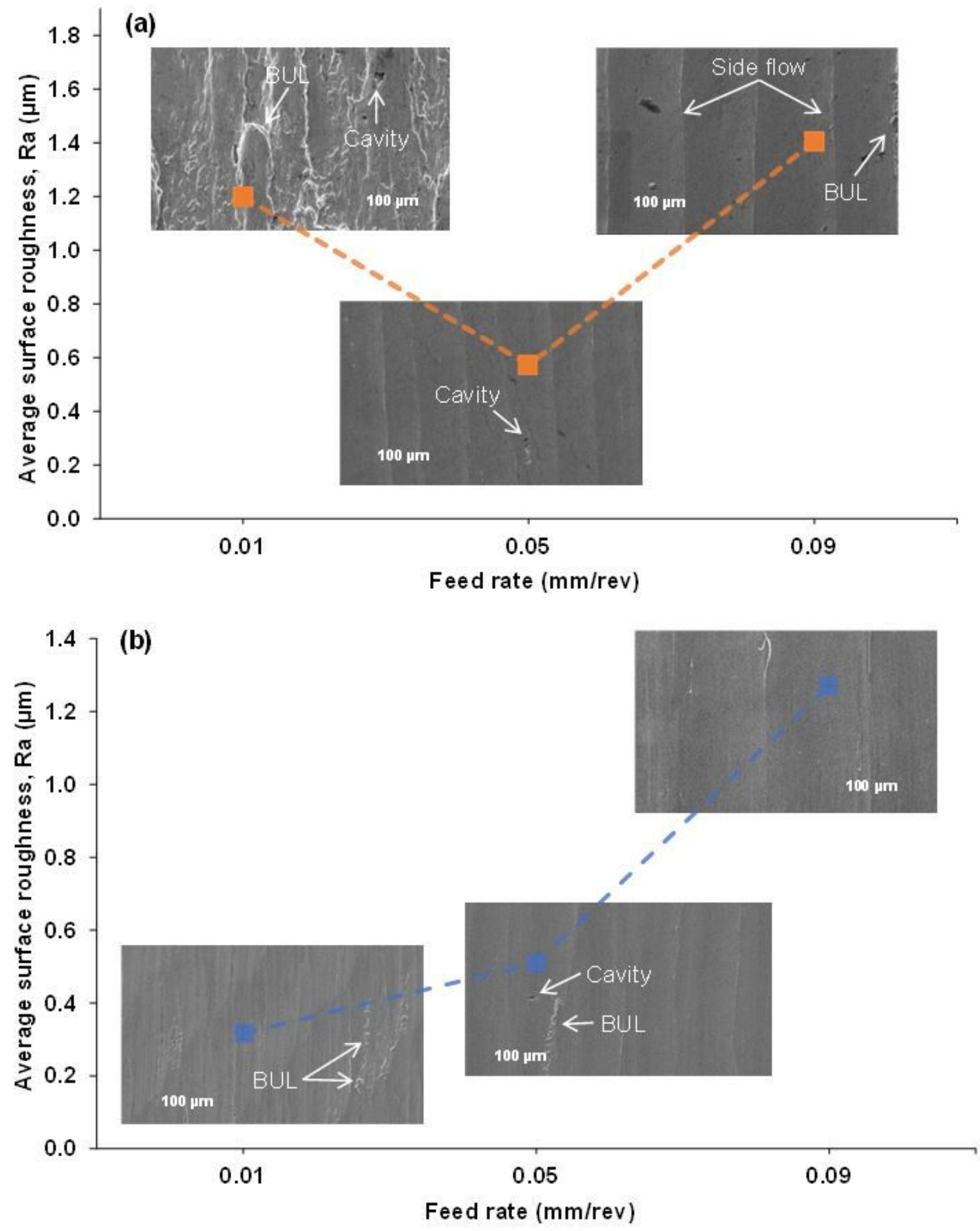

Figure 11

Variation of surface quality with feed rate $(\mathrm{Vc}=70 \mathrm{~m} / \mathrm{min}$, ap $=0.5 \mathrm{~mm})$ under (a) cryogenic, (b) flooded cutting conditions. 

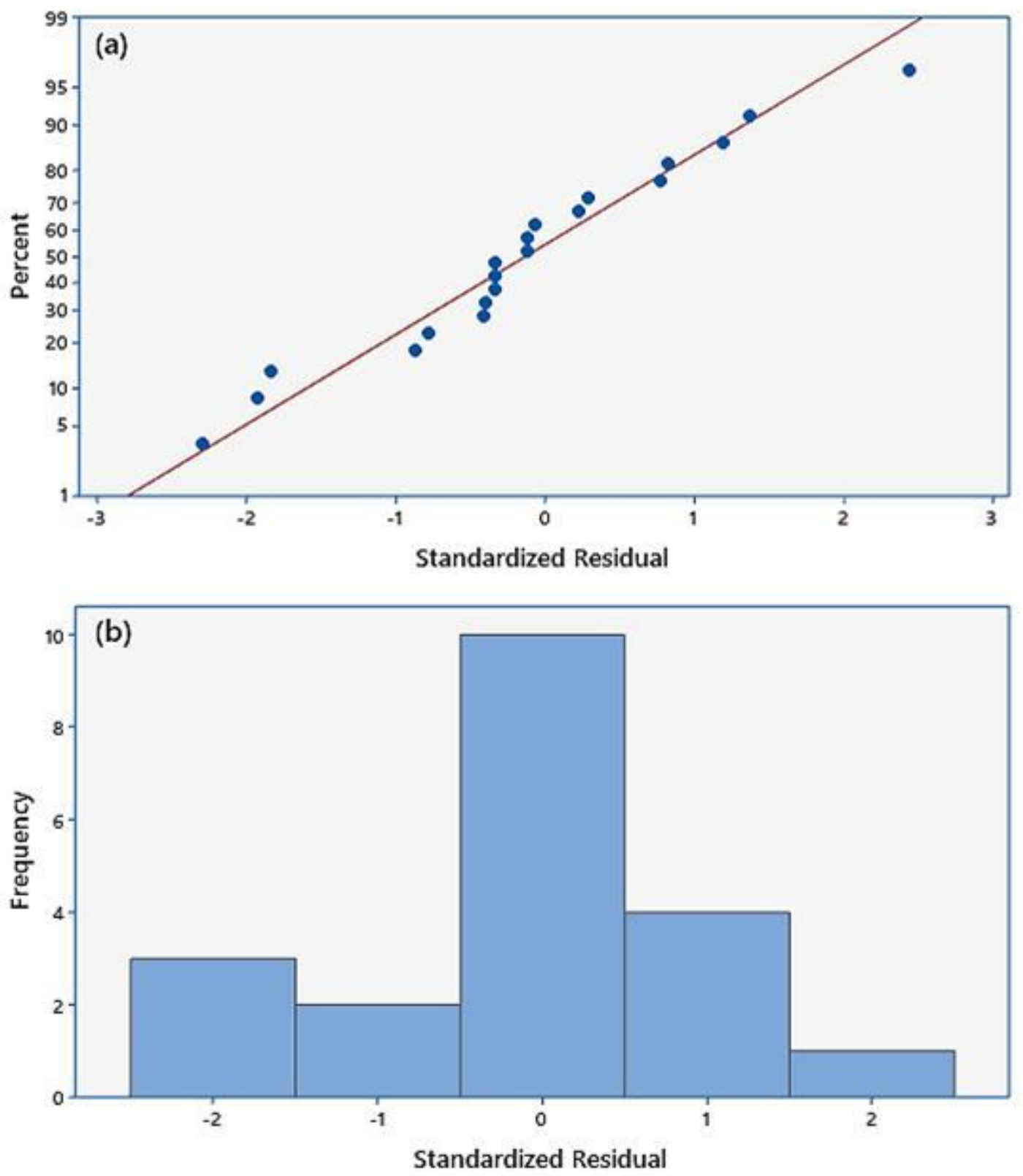

Figure 12

(a) Normal probability plot, (b) histogram of standardized residual for cutting force. 


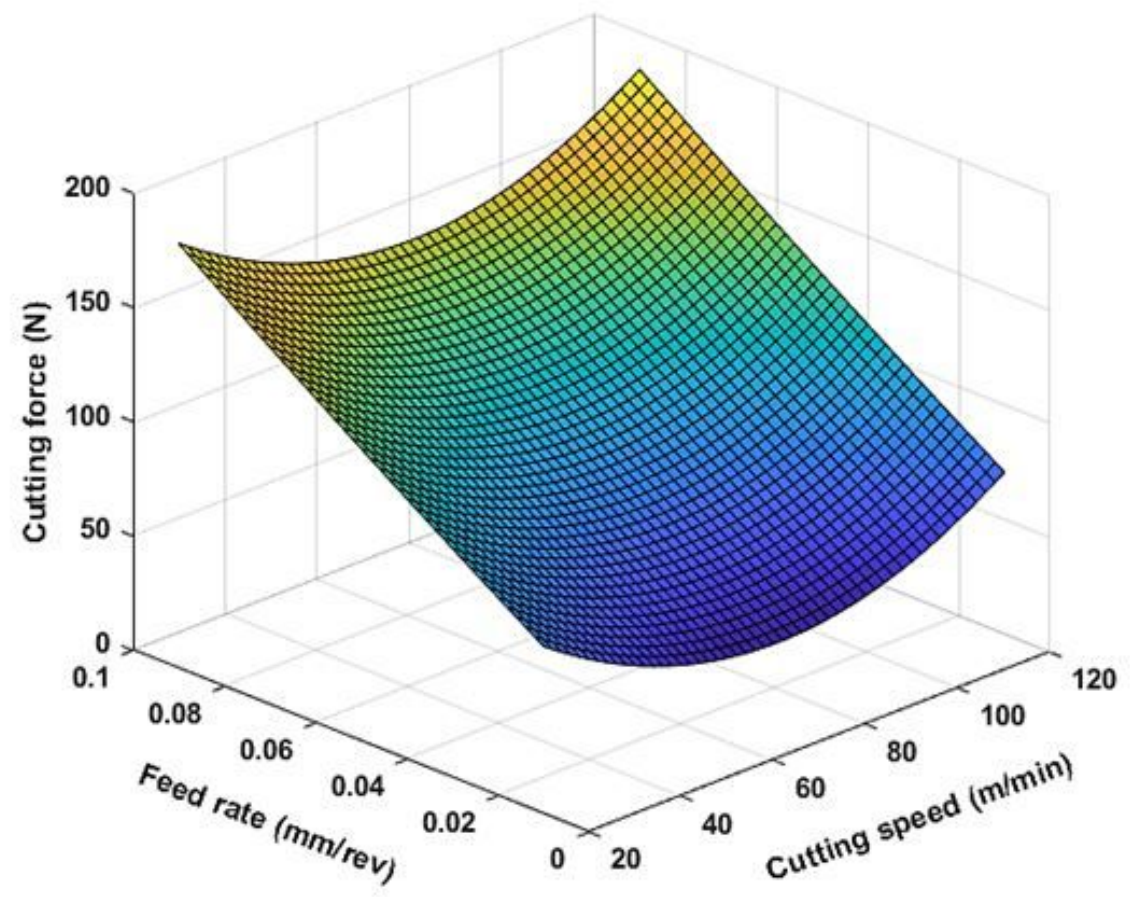

(a)

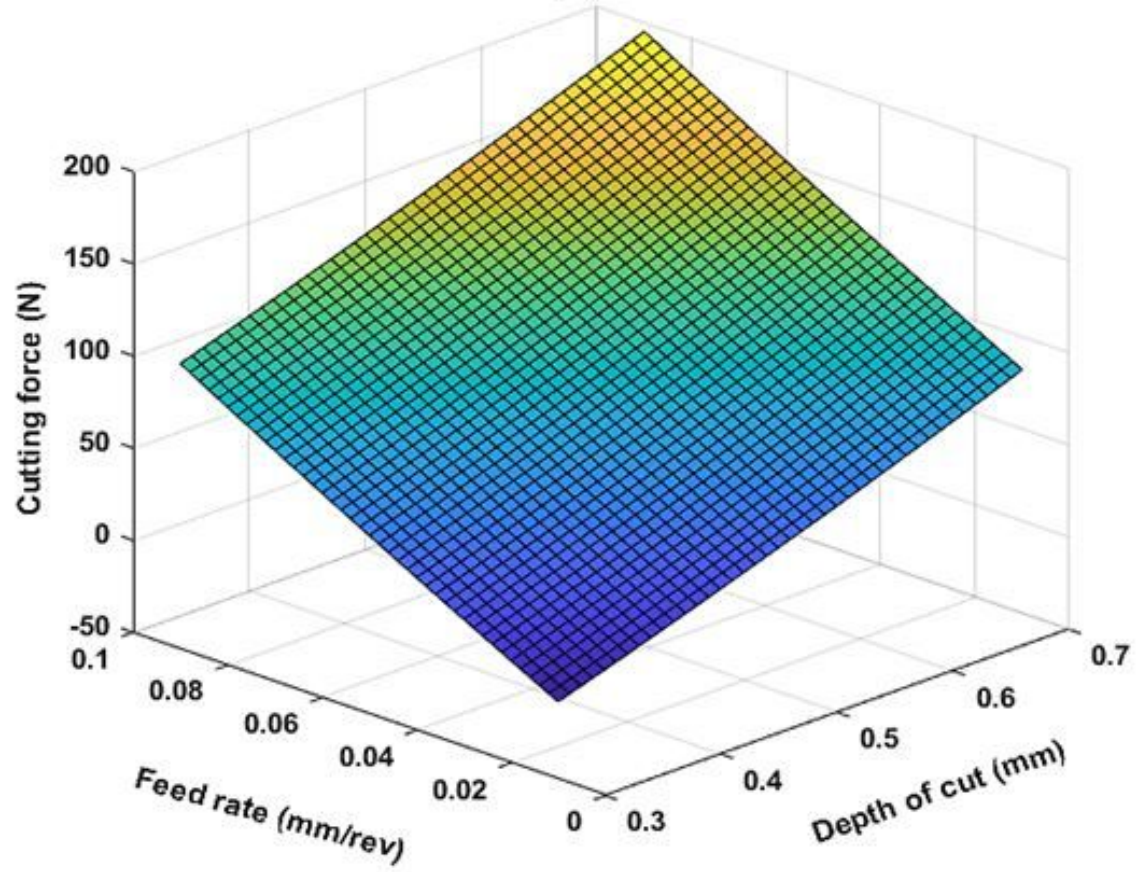

(b)

Figure 13

3D surface graph for interaction effect of (a) cutting speed and feed rate and (b) feed rate and depth of cut on cutting force. 

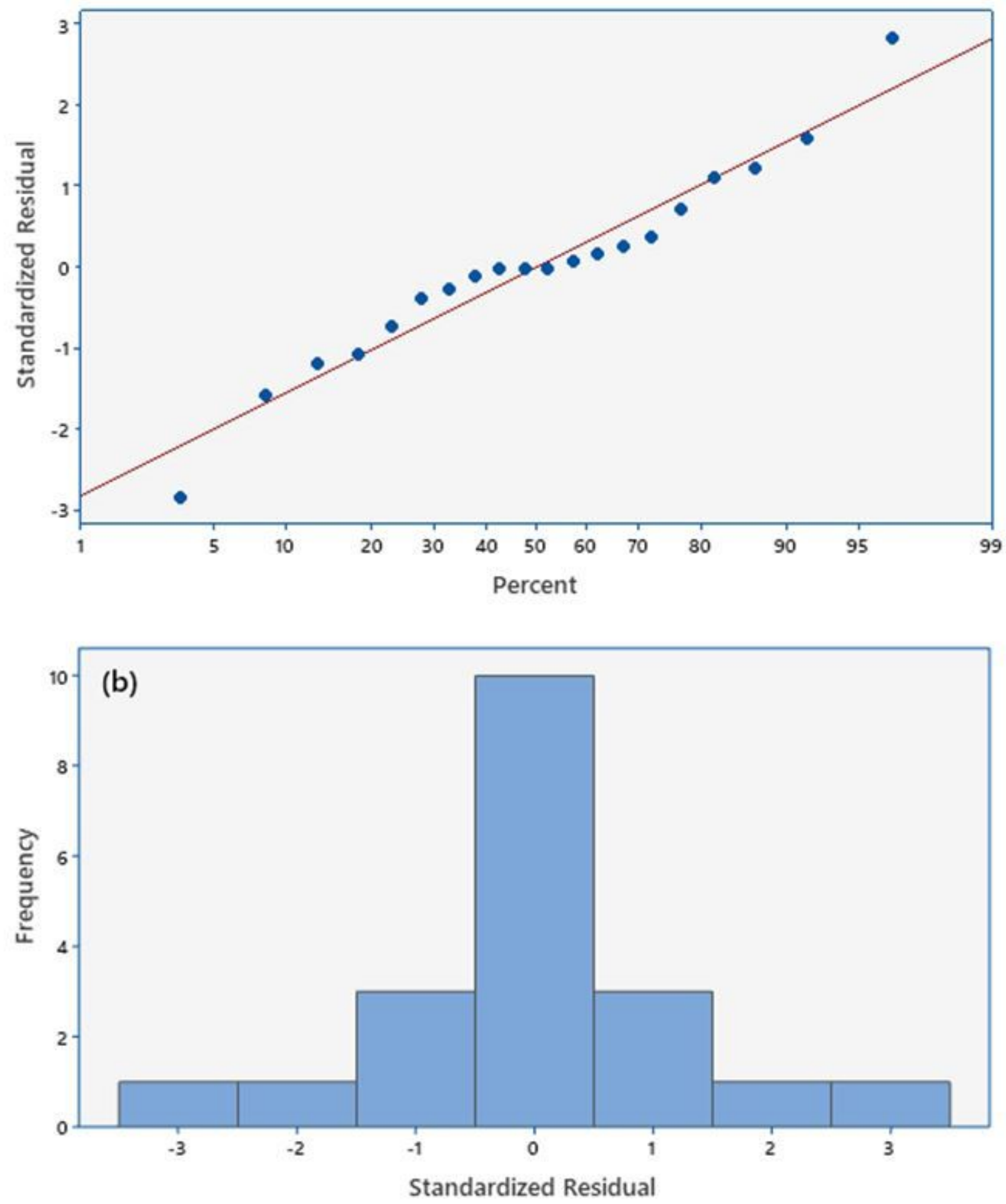

Figure 14

(a) Normal probability plot, (b) histogram of standardized residual for flank wear. 


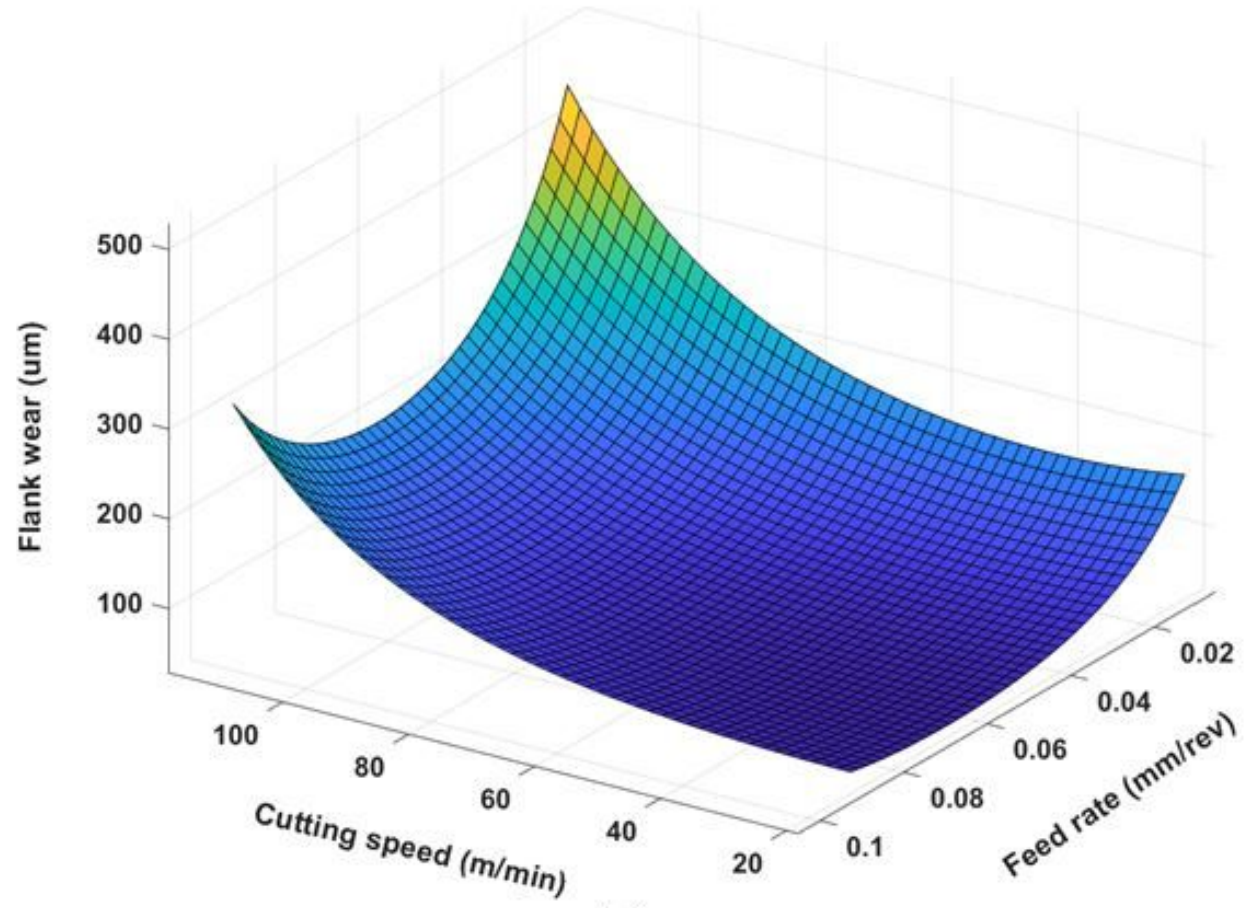

(a)

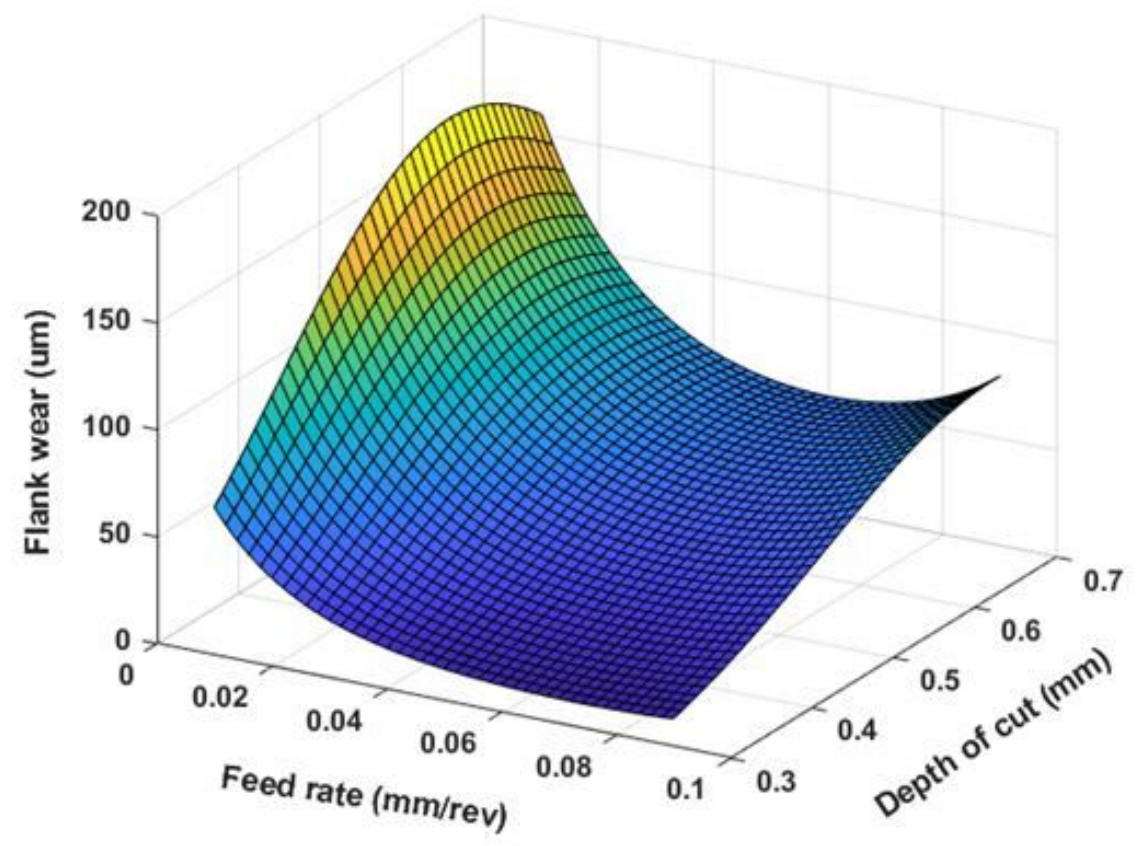

(b)

\section{Figure 15}

3D surface graph for interaction effect of (a) cutting speed and feed rate and (b) feed rate and depth of cut on flank wear. 

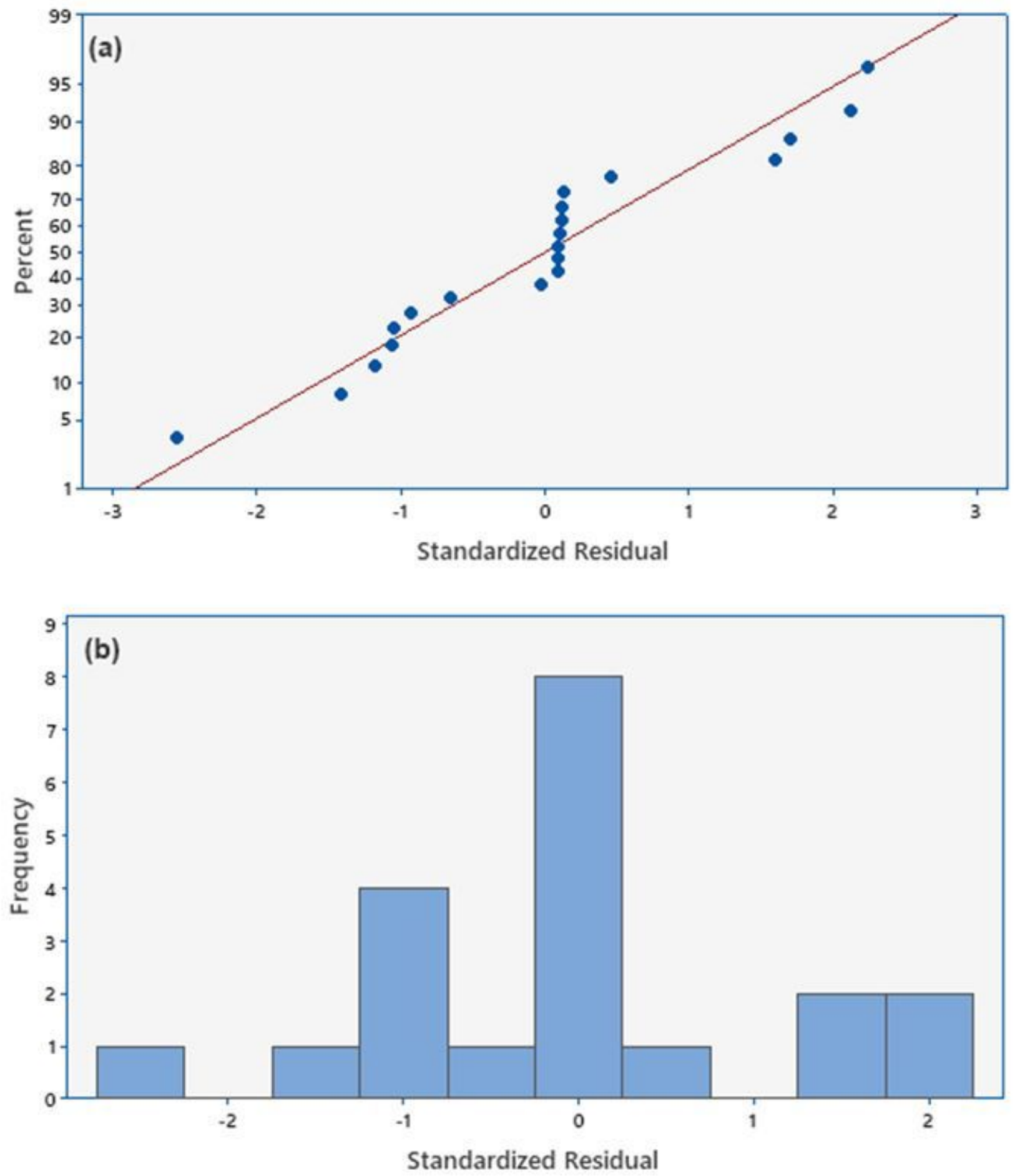

Figure 16

(a) Normal probability plot, (b) histogram of standardized residual for Ra surface roughness. 


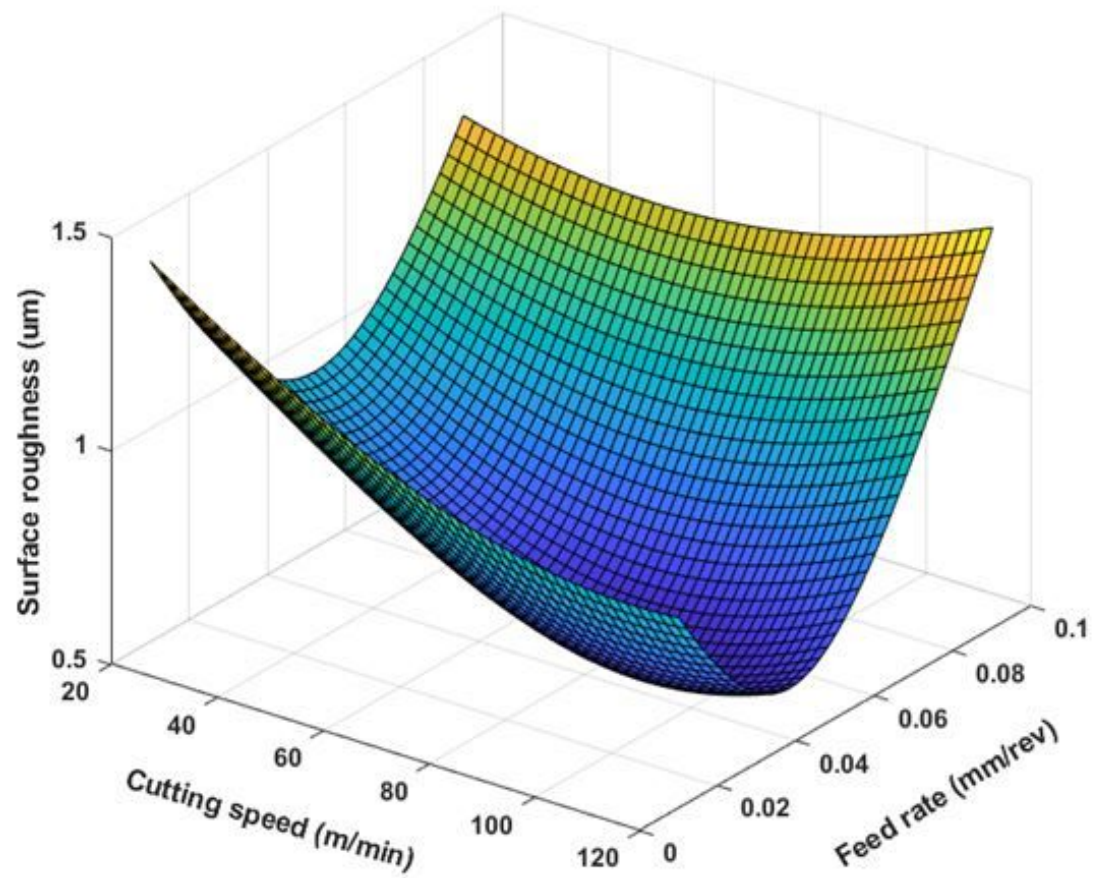

(a)

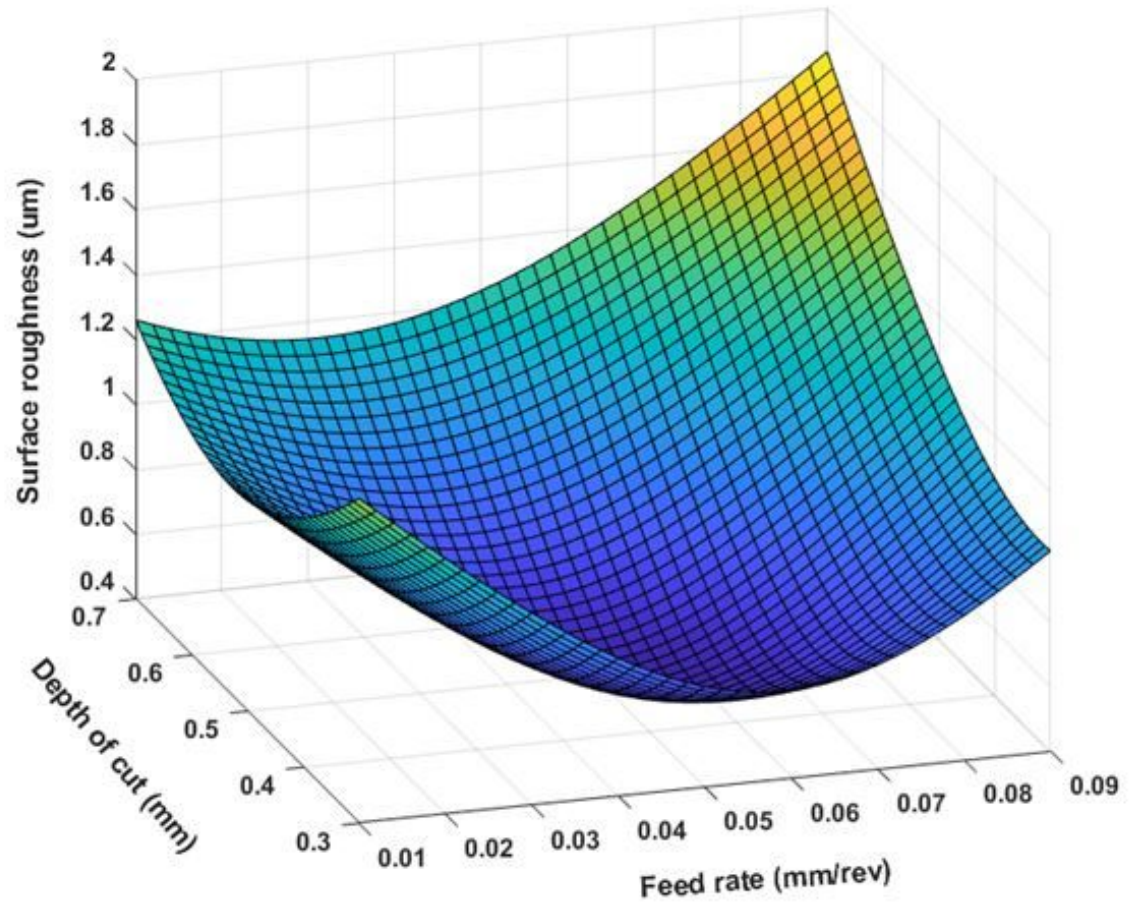

(b)

Figure 17

3D surface graph for interaction effect of (a) cutting speed and feed rate and (b) Feed rate and depth of cut on Ra surface roughness. 